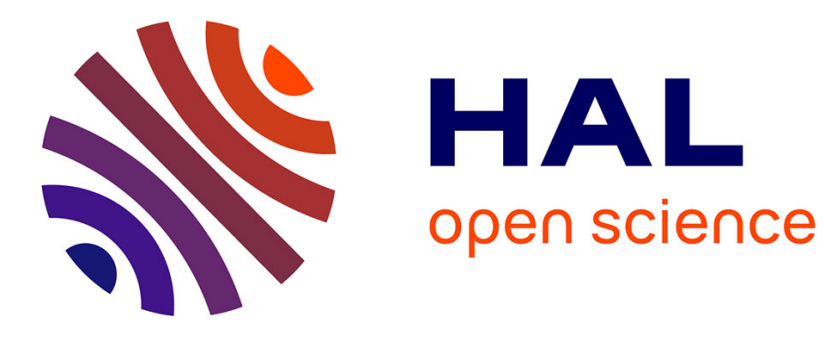

\title{
The dispersive velocity of compressional waves in magmatic suspensions
}

Alexandre Carrara, Philippe Lesage, Alain Burgisser, Catherine Annen, George W Bergantz

\section{- To cite this version:}

Alexandre Carrara, Philippe Lesage, Alain Burgisser, Catherine Annen, George W Bergantz. The dispersive velocity of compressional waves in magmatic suspensions. Geophysical Journal International, 2021, 10.1093/gji/ggab432 . hal-03418127

\section{HAL Id: hal-03418127 \\ https://hal.science/hal-03418127}

Submitted on 6 Nov 2021

HAL is a multi-disciplinary open access archive for the deposit and dissemination of scientific research documents, whether they are published or not. The documents may come from teaching and research institutions in France or abroad, or from public or private research centers.
L'archive ouverte pluridisciplinaire HAL, est destinée au dépôt et à la diffusion de documents scientifiques de niveau recherche, publiés ou non, émanant des établissements d'enseignement et de recherche français ou étrangers, des laboratoires publics ou privés. 
3 Alexandre Carrara ${ }^{1,2, *}$, Philippe Lesage ${ }^{2}$, Alain Burgisser ${ }^{2}$, Catherine Annen $^{2,3}$, George W. Bergantz ${ }^{1}$

4

$5{ }^{1}$ Department of Earth and Space Sciences, Box 35310, University of Washington, Seattle, WA 98195 , 6 USA.

7

$8{ }^{2}$ Univ. Grenoble Alpes, Univ. Savoie Mont Blanc, CNRS, IRD, UGE, ISTerre, 38000 Grenoble, 9 France.

10

$11{ }^{3}$ Institute of Geophysics, Czech Academy of Sciences, Prague, Czech Republic.

12

13 *Corresponding author: carrara.alexandre.univ@gmail.com 


\section{Abstract:}

The geophysical detection of magma bodies and the estimation of the dimensions, physical

16 properties, and the volume fraction of each phase is required to improve the forecasting of volcanic

17 hazards and understanding of transcrustal magmatism. We develop an analytical model to calculate the

18 speed of sound in a magma consisting of crystals and gas bubbles suspended in a viscous melt. We

19 apply our model to calculate the speed of sound as a function of the temperature in three magmas with

20 different chemical compositions, representative of the diversity that may be encountered in arc

21 magmatism. The model employs the coupled phase theory that explicitly accounts for the exchange of

22 momentum and heat between the phases. We show that the speed of sound varies non-linearly with the

23 frequency of an acoustic perturbation between two theoretical bounds. The dispersion of the sound in a

24 magma results from the exchange of heat between the melt and dispersed phases that affects the

25 magnitude of their thermal expansions. The lower bound of the sound speed occurs at low frequencies

26 where all the constituents can be considered in thermal equilibrium, whereas the upper bound occurs at

27 high frequencies for which the exchange of heat between the phases may be neglected. The presence of

28 gas in a magma produces a sharp decrease in the velocity of compressional waves and generates

29 conditions in which the dispersion of the sound is significant at the frequencies usually considered in

30 geophysics. Finally, we compare the estimates of our model with the one from published relationships.

31 Differences are largest at higher frequencies and are $<10 \%$ for typical magma.

32

33 Key words: Acoustic properties; Body waves; Physics of magma and magma bodies; Volcano 34 seismology. 


\section{I introduction}

The possible reintrusion of crystal-rich magma reservoirs with crystal-poor magmas (e.g. Caricchi et al. 2014, Annen et al. 2015, Wiebe 2016, Carrara et al. 2020), the crystal content of eruptive products (e.g. Pallister et al. 1996, Eichelberger \& Izbekov 2000, Takahashi \& Nakagawa 2013), and the occurrence of mechanisms leading to the extraction of melt or exsolved volatiles from crystal-rich reservoirs (e.g. Bachmann \& Bergantz 2004, Huber et al. 2011, Parmigiani et al. 2016, Holness 2018, Bachmann \& Huber 2019, Degruyter et al. 2019) are evidences of the episodic existence in upper crustal magma reservoirs of volumes dominated by the presence of fluids. The crystals and exsolved volatiles of a magma affect its rheology (e.g. Caricchi et al. 2007, Petford 2009, Mader et al. 2013) and can dramatically change eruptive styles (e.g. Karlstrom et al. 2012, Cassidy et al. 2018). When the solid volume fraction reaches a threshold, crystals start to touch each other, forming a semi-rigid skeleton inhibiting magma flow (Bergantz et al. 2017). As a result, the volumes dominated by the presence of fluids likely represent the eruptible portions of the reservoir. Therefore, the detection of such volumes and the estimation of the volume fraction of each phase and is of paramount importance to enhance our ability to predict the occurrence and style of eruptions and to best assess volcanic hazards.

Among geophysical methods, tomography of seismic wave velocities and attenuations has been widely employed to map magma reservoirs but has not clearly evidenced the presence of fluiddominated bodies (Waite \& Moran 2009, Paulatto et al. 2012, De Siena et al. 2014, Huang et al. 2015, Delph et al. 2017, Kiser et al. 2018, Hooft et al. 2019). Tomography images are computed with the first wave arrival at the stations, which corresponds to the fastest travel from the source. The velocities of compressional waves (also called sound speed) are lower in fluid-rich magmas. As a result, the ray paths of the first arrivals may circumvent and undersample such volumes in the resulting images. The spatial averaging of the seismic properties resulting from tomography may also smooth the effects of 
58 the presence of small fluid bodies, which are then interpreted as partially molten rocks. Finally, seismic

59 waves may be attenuated during their propagation across the magma reservoir. Hence, improving our

60 knowledge of the acoustic properties of the materials constituting the magma reservoir can reduce the

61 uncertainties in interpretation.

63 in partially molten rocks (e.g. Mavko 1980, Hammond \& Humphreys 2000, Takei 2002, Hier-

64 Majumder 2008, Carcione et al. 2020) or in bubbly melts (e.g. Chouet 1996, Kumagai \& Chouet 2000,

65 Morrissey \& Chouet 2001, Neuberg \& O’Gorman 2002, Collier et al. 2006, Karlstrom \& Dunham

66 2016), no model addresses the acoustic properties of magmas composed of crystals and gas bubbles

67 suspended in the melt. Here we aim at calculating the velocity of a compressional wave at the

68 frequencies used in volcano seismology $(\sim 0.001-1000 \mathrm{~Hz})$ in a three-phase suspension composed of

69 solids and gas bubbles suspended in a viscous liquid. Previous models for the acoustic properties of a

70 suspension employed methods based on the effective medium theory (e.g. Kuster \& Toksöz 1974,

71 Berryman 1980) because they are applicable at any frequency, and account for the presence of an

72 unlimited number of phases. However this approach neglects, the influence of the liquid phase

73 viscosity, the relative motion (or relative velocity) between the constituents, the evolution of the

74 temperature of the phases, and the interaction between neighboring solids grazing each other.

75 Alternatively, methods using the coupled phase theory (e.g. Harker \& Temple 1988, Atkinson \&

76 Kytömaa 1992, Margulies \& Schwarz 1994, Kytömaa 1995, Evans \& Attenborough 1997, Valier-

77 Brasier et al. 2015) can capture all these effects for bi-phasic suspensions (e.g. solids in a liquid or

78 bubbles in a liquid) but are restricted to the long-wavelength approximation (wavelength of the

79 perturbation much larger than the size of the discrete phases). The coupled phase theory is, therefore,

80 suitable to compute the acoustic properties of magmas because the long-wavelength approximation is 
81 always valid at the frequencies used in geophysics. To be extended to a three-phase magma, the method

82 requires modifications to account for both viscous and thermal effects and the joint presence of crystals 83 and gas bubbles.

84 Here, we adapt the coupled phase theory to the computation of the velocity of compressional 85 waves traveling in magmas where the crystals are not touching each other and where the melt is the 86 carrier phase. We first introduce the conservation equations controlling the propagation of an acoustic 87 perturbation in a suspension and present the calculation of the speed of sound using the coupled phase

88 theory. The resulting model allows us to compute both the velocity and intrinsic attenuation coefficient 89 of compressional waves. In this work, we focus on the speed of sound and we will address attenuation 90 in a future communication. Results are first presented for a suspension representative of magmas to 91 illustrate how its composition and the characteristics of the perturbation (frequency and propagation 92 direction) affect the speed of sound. We then apply the model to magmas having different chemical 93 compositions representative of arc magmatism to highlight the key features of the propagation of sound 94 in magmas. Finally, we compare the results of our model with other relationships proposed or 95 employed by authors to estimate the speed of sound in magmas. 


\section{II Method}

To present the model, we first introduce the physical model and assumptions about the initial

99 conditions (section II.1). Then, we introduce the conservation equations describing the dynamics of the 100 phases (section II.2). These equations are similar to those reported in the literature (e.g. Harker \& 101 Temple 1988, Atkinson \& Kytömaa 1992, Evans \& Attenborough 1997) and include a few 102 modifications to account for the presence of three phases and the dynamic viscosity of the melt. The 103 details of the derivation of these equations are presented in supplementary material 1 (online). In 104 section II.3 we present the relationships controlling the transfer momentum between the phases and 105 within the liquid and solid phases. Section II.4 details the relationship we used to account for the 106 transfer of heat within the liquid phase and between the carrier and suspended phases. Section II.5 107 describes briefly the calculation of the speed of sound using the coupled phase theory. We employed 108 the same method as presented and employed by several authors to calculate the velocity of a 109 compressional wave from the(e.g. Harker \& Temple 1988, Atkinson \& Kytömaa 1992, Evans \& 110 Attenborough 1997). We detail the calculation of the speed of sound in supplementary information 2 111 (online). In section II.6, we derive the bounds of the speed of sound in magma using an alternative 112 approach considering an isotropic compression of an isolated volume of magma. Finally, we present the 113 initial composition of the magmas and how the evolution of their physical properties change as a 114 function of temperature are computed (section II.7).

\section{II.1 Physical model}

We consider an elementary volume of a suspension composed of solid particles and gas bubbles

118 in a viscous liquid (Fig. 1). Both discrete phases are represented with monodisperse spheres. For the 119 initial conditions, we consider all the constituents of the suspension to be static and in thermodynamic 
120 equilibrium. The thermodynamic properties of each phase (e.g. bulk modulus or heat capacity) are

121 considered uniform within the elementary volume and constant with pressure and temperatures. The 122 presence of mass transfer or chemical reactions between the phases is neglected.

123 A plane and monochromatic compressional wave propagates in the direction $x$ with an angle $\theta$

124 from the horizontal with respect to the gravitational acceleration (Fig. 1). The geometry of the acoustic

125 perturbation allows us to express the conservation equations describing the dynamics of each phase in 126 one dimension aligned with the propagation direction $x(\partial y=\partial z=0)$. The wave has a small amplitude 127 and a frequency in the range of the acoustic signals recorded in nature $(0.001-1000 \mathrm{~Hz})$ for which its 128 wavelength is much larger than the diameters of the particles and bubbles. Therefore, the scattering of 129 the acoustic wave resulting from resonance effects in the discrete solids and bubbles may be neglected 130 (Atkinson \& Kytömaa 1992).

\section{II.2 Conservation equations}

The propagation of an acoustic perturbation in the suspension is governed by the conservation

134 equations of each phase. Neglecting the transfer of mass between the phases and chemical reactions,

135 the conservation of mass of the liquid phase reads:

$$
\partial_{t}\left(\phi_{l} \rho_{l}\right)+\partial_{x}\left(\phi_{l} \rho_{l} u\right)=0
$$

137 where $\rho_{l}$ is the density of the liquid phase, $\phi_{l}$ is the volume fraction of liquid in the suspension, and $u$ is

138 the liquid velocity in the direction $x\left(u=u_{x}\right.$, the velocities in the other directions are null because we 139 consider a plane wave and the suspension to be initially static). Similarly, for the solid and gas phases, 140 mass conservations are:

$141 \partial_{t}\left(\phi_{s} \rho_{s}\right)+\partial_{X}\left(\phi_{s} \rho_{s} v\right)=0$, 
143 where $\rho_{s}$ is the density of the solids, $\phi_{s}$ is the volume fraction of solids, $v$ is the velocity of the solids in

144 the direction $x, \rho_{g}$ is the gas density, $\phi_{g}$ is the volume fraction of gas, and $w$ is the velocity of the gas 145 bubbles.

The rate of change of momentum of the liquid equals the sum of the applied force and may be expressed as (see supplementary material 1, online):

$$
\phi_{l} \rho_{l}\left(\partial_{t}(u)+u \partial_{X}(u)\right)+\phi_{l} \partial_{X}(P)+I_{l l}+I_{l s}+I_{l g}+\phi_{l} \rho_{l} g \sin \theta=0
$$

149 where $P$ is the pressure, $I_{l l}$ is the rate of momentum exchange among the liquid, $I_{l s}$ is the rate of 150 momentum exchange between the liquid and solid phases, $I_{l g}$ is the rate of momentum exchange 151 between the liquid and gas phases, and $g$ is the gravitational acceleration. The exchange of momentum 152 within the liquid, $I_{l l}$, is equal to the divergence of the viscous stress tensor and indicates the rate at 153 which the viscous stress propagates in the liquid. The two other terms, $I_{l s}$ and $I_{l g}$, expresses the 154 exchanges of momentum between the carrier and discrete phases through the drag forces when they 155 experienced relative velocities. The conservation of momentum in the solid phases is:

$$
\phi_{s} \rho_{s}\left(\partial_{t}(v)+{ }_{v} \partial_{x}(v)\right)+\phi_{s} \partial_{x}(P)+I_{S S}-I_{l s}+\phi_{s} \rho_{s} g \sin \theta=0
$$

157 where $I_{s s}$ represents the transfer of momentum between close solids. Here this term corresponds to the 158 lubrication forces relating to the squeezing of the interstitial liquid located between two grazing 159 particles (see next section for details about this term). The momentum conservation in the gas phase 160 reads:

$$
\phi_{g} \rho_{g}\left(\partial_{t}(w)+W \partial_{X}(w)\right)+\phi_{g} \partial_{X}(P)-I_{l g}+\phi_{g} \rho_{g} g \sin \theta=0
$$




$$
\begin{gathered}
\phi_{1} \rho_{l} C_{P l}\left(\partial_{t}\left(T_{l}\right)+u \partial_{x}\left(T_{l}\right)\right)-\phi_{1} T_{l} \alpha_{l}\left(\partial_{t}(P)+u \partial_{X}(P)\right)+2 \phi_{l} \rho_{l} g u \sin \theta \\
-\overline{\overline{\sigma_{X X}}} \partial_{x}(u)+H_{l l}+H_{l s}+H_{l g}=0
\end{gathered}
$$

165 where $T_{l}$ is the temperature of the liquid phase, $C_{P l}$ is the specific heat capacity at a constant pressure of 166 the liquid, $\alpha_{l}$ is the coefficient of thermal expansion of the liquid, $\overline{\bar{O}}$ is the liquid viscous stress tensor, $167 H_{l l}$ is the rate of heat diffusion within the liquid phase by conduction, $H_{l s}$ is the rate of heat exchange 168 between the carrier liquid and discrete solids, and $H_{l g}$ is the rate of heat exchange between the liquid 169 and gas bubbles. The two terms $H_{l s}$ and $H_{l g}$ are the total heat flux over the interfaces between the carrier 170 and discrete phases and depend on the temperature difference between constituents. Similarly, in the 171 solid and gas phases, the conservation of energy is:

$$
\phi_{s} \rho_{s} C_{P_{s}}\left(\partial_{t}\left(T_{s}\right)+{ }_{v} \partial_{x}\left(T_{s}\right)\right)-\phi_{s} T_{s} \alpha_{s}\left(\partial_{t}(P)+{ }_{V} \partial_{x}(P)\right)+2 \phi_{s} \rho_{s} g v \sin \theta-H_{l s}=0
$$

$$
\phi_{g} \rho_{g} C_{P g}\left(\partial_{t}\left(T_{g}\right)+W \partial_{x}\left(T_{g}\right)\right)-\phi_{g} T_{g} \alpha_{g}\left(\partial_{t}(P)+W \partial_{X}(P)\right)+2 \phi_{g} \rho_{g} g w \sin \theta-H_{l g}=0 \quad,(9)
$$

174 where $T_{s}$ is the temperature of the solids, $T_{g}$ is the temperature of the gas, $C_{P s}$ is the specific heat 175 capacity at a constant pressure of the particles, $C_{P g}$ is the specific heat capacity of the gas, $\alpha_{s}$ is the 176 coefficient of thermal expansion of the solid particles, and $\alpha_{g}$ is the coefficient of thermal expansion of 177 the gas.

179 temperatures and pressure:

$$
d \rho_{l}-\frac{\rho_{l}}{K_{l}} d P+\alpha_{1} \rho_{l} d T_{l}=0
$$

181

$$
d \rho_{s}-\frac{\rho_{s}}{K_{s}} d P+\alpha_{s} \rho_{s} d T_{s}=0
$$

182

$$
d \rho_{g}-\frac{\rho_{g}}{K_{g}} d P+\alpha_{g} \rho_{g} d T_{g}=0
$$


183 where $K_{l}$ is the bulk modulus of the liquid phase (inverse of the coefficient of isothermal 184 compressibility), $K_{s}$ is the bulk modulus of the solids, and $K_{g}$ is the bulk modulus of the gas. The last 185 conservation equation ensures that the sum of the volume fraction of all the phases is always equal to 186 one. In differential form, it reads:

$$
\partial_{t}\left(\phi_{1}\right)+\partial_{t}\left(\phi_{s}\right)+\partial_{t}\left(\phi_{g}\right)+u \partial_{x}\left(\phi_{I}\right)+v \partial_{x}\left(\phi_{s}\right)+{ }_{W} \partial_{x}\left(\phi_{g}\right)=0 \quad .
$$

\section{II.3 Interphase exchanges of momentum}

The exchange of momentum within the liquid phase, $I_{l l}$, is equal to the divergence of the viscous

stress tensor, $\overline{\bar{\sigma}}$, which depends on the dynamic shear viscosity, $\eta$, and volume viscosity, $\lambda$, of the

191 liquid $\left(I_{l l}=\phi \nabla \cdot \eta \overline{\bar{\epsilon}}+\lambda t r|\overline{\bar{\epsilon}}| \overline{\bar{I}}\right]$, where $\overline{\bar{\epsilon}}$ is the strain rate tensor and $\overline{\bar{I}}$ is the unit tensors). For a 192 magmatic melt in relaxed conditions (low-frequency perturbations) Dingwell \& Webb (1989), showed

193
that $\lambda=\eta / 3$. Since the velocity of the liquid in the directions $y$ and $z$ are null, the rate of momentum exchange in the liquid can be calculated as:

$195 \quad I_{l l}=\frac{7}{3} \phi_{1} \eta \partial_{x}^{2}(u)$.

While contacts are neglected, crystals can exchange momentum through lubrication forces

197 (Marzougui et al. 2015, Bergantz et al. 2017, Carrara et al. 2019). Lubrication refers to the 198 hydrodynamic forces resulting from the resistance of the liquid located in the gap between two 199 neighboring particles to their relative motions. These forces influence the duration of the initiation and 200 closure of motion of the solid phase (Carrara et al. 2019). The propagation of a wave in a suspension 201 can be viewed as a "transient steady-state" in which the relative motions between neighboring solids 202 are repetitively initiated and dissipated. To derive an expression of the rate of momentum exchange 203 between the solids, $I_{s s}$, we consider a suspension where spherical particles are regularly organized 204 forming a hexagonal close-packed lattice (Fig. 2). In this configuration, the distances between the 
205 particles are identical and minimized such that the influence of lubrication is maximized. The solid 206 lattice is oriented along the direction of propagation of the wave $(x)$ such that it can be represented as 207 three layers of particles orthogonal to the direction $x$ (Fig. 2). The total lubrication force between two 208 neighboring particles (here labeled as $i$ and $k$ ) including both normal and tangential components can be 209 expressed as (Marzougui et al. 2015, Carrara et al. 2019):

$210 \quad F_{l u b}(k, i)=\frac{3 \eta A}{\rho_{s} d_{s}^{2}}\left(v_{k}-v_{i}\right)$,

211 where $A$ is a geometrical parameter indicating the relative importance between normal and tangential 212 lubrication forces that depends on the distance between the surface of the particles and on the grazing 213 angle $\beta$ (Carrara et al. 2019):

$214 A=\frac{3 \cos \beta}{2 j}-\ln (j) \sin \beta$,

215 where $j$ is the ratio between the distance separating the surface of the neighboring particles and their 216 radius. Both the incidence angle and distance between the surface of the particles can be deduced from 217 geometrical arguments since the solid lattice is regular. For a compressional wave $\beta=(2 / 3)^{1 / 2}$ and $j$ is 218 related to the volume fraction of solids by (Atkinson \& Kytömaa 1992):

$219 j=1-\left(\frac{\phi_{s}}{\phi_{s \max }}\right)^{\frac{1}{3}}$,

220 where $\phi_{s \max }$ is the maximum volume fraction at which the solids start to touch each other. For a 221 hexagonal close-packed lattice, $\phi_{s \max }=0.64$. Summing all the lubrication interaction experienced by the 222 particle located on the second layer in Fig. 2 gives:

223

$$
F_{l u b}^{\text {tot }}(2)=\frac{9 \eta A}{\rho_{s} d_{s}^{2}}\left(v_{1}+v_{3}-2 v_{2}\right),
$$


224 where $v_{1}, v_{2}$, and $v_{3}$ are the velocity of the particles in the layer 1, 2, and 3 in Fig. 2, respectively. The

225 sum of the solid velocities on the right-hand side of Eq. (18) may be approximated with the second-

226 order derivative in space of the solid velocity:

$227 \quad \frac{\partial^{2} v_{x}}{\partial x^{2}} \simeq \frac{\left(v_{1}+v_{3}-2 v_{2}\right)}{\Delta_{x}^{2}}$,

228 where $\Delta_{x}$ is the distance in the direction $x$ separating two successive layers of solids in Fig. 2, which 229 can be calculated as:

$230 \quad \Delta_{x}=\sqrt{\frac{2}{3}} d_{s}\left(\frac{j}{2}+1\right)$.

231 Inserting Eqs. (19-20) into Eq. (18) gives the following expression for the exchange of momentum 232 between the solids:

$233 \quad I_{s s}=F_{l u b} \simeq \frac{6 \eta A\left(\frac{j}{2}+1\right)^{2}}{\rho_{s}} \frac{\partial^{2} V}{\partial x^{2}}$.

234 The liquid exchanges momentum with the other phases (particles and bubbles) because of their 235 relative motions. The transfers of momentum between the carrier and discrete phases include both 236 steady (drag) and unsteady (added mass and Basset forces) contributions. Because of the viscosity of 237 magmatic melts, the frequency range considered here is well below those at which unsteady forces 238 become significant compared to the steady contribution (Gumerov et al. 1988, Atkinson \& Kytömaa 239 1992). Therefore, the rate of momentum exchange between the liquid and solid phases can be reduced 240 to the steady term (Gidaspow 1994):

$241 \quad I_{l s}=\beta_{l s}(u-v)$,

242 and the rate of momentum exchange between liquid and bubbles is:

$243 \quad I_{l g}=\beta_{l g}(u-W)$, 
244 where $\beta_{l s}$ is the coefficient of momentum exchange between the liquid and solids and $\beta_{l g}$ is the

245 coefficient of momentum exchange between the liquid and gas phases. To compute these two

246 coefficients, several empirical correlations exist in the literature (e.g. Ergun 1952, Wen \& Yu 1966,

247 Syamlal et al. 1993, Gidaspow 1994, Benyahia et al. 2006). Here, we combine a Stokes drag law for

248 high porosity (high liquid volume fraction) and an Ergun relationship at lower liquid volume fraction.

249 Because of the high viscosity of the liquid phase, the Ergun drag law may be reduced to the Carman-

250 Kozeny relationship because the inertial term becomes negligible:

$251 \quad \beta_{l s}=\left\{\begin{array}{ll}\frac{18 \eta \phi_{s}}{d_{s}^{2}} & \text { if } \phi_{l}>\frac{25}{28} \\ \frac{150 \phi_{s}^{2} \eta}{\phi_{l} d_{s}^{2}} & \text { if } \phi_{l} \leq \frac{25}{28}\end{array}\right.$,

$252 \quad \beta_{l g}=\left\{\begin{array}{ll}\frac{18 \eta \phi_{g}}{d_{g}{ }^{2}} & \text { if } \phi_{l}>\frac{25}{28} \\ \frac{150 \phi_{g}{ }^{2} \eta}{\phi_{l} d_{g}{ }^{2}} & \text { if } \phi_{l} \leq \frac{25}{28}\end{array}\right.$,

253 where $d_{s}$ is the diameter of the solid particles and $d_{g}$ is the diameter of the gas bubbles. The drag laws

254 we used here are similar to the one proposed by Gidaspow (1994), but uses the Stokes drag instead of

255 the Wen-Yu drag correlation at high porosity such that the drag forces are linearly dependent on the

256 relative velocities between the phases, which is suitable for the coupled phase theory.

257

258

259

\section{II.4 Interphase exchanges of heat}

The amount of heat transferred within the carrier liquid by conduction is calculated using

260 Fourier's law:

$261 \quad H_{l l}=\phi_{1} k_{l} \partial_{x}^{2}\left(T_{l}\right)$, 
262 where $k_{l}$ is the heat conductivity of the liquid.

263 The rate of heat exchange between the carrier and discrete phases are expressed by:

$264 H_{l s}=\gamma_{l s}\left(T_{l}-T_{s}\right)$

265 and,

$266 \quad H_{l g}=\gamma_{l g}\left(T_{l}-T_{g}\right)$,

267 where $\gamma_{l s}$ is the coefficient of heat transfer between the fluid and solids, and $\gamma_{l g}$ is the coefficient of heat

268 exchange between the fluid and gas. In the absence of mass transfer between the phases, the 269 coefficients of heat transfer can be estimated as (Syamlal et al. 1993):

$270 \quad \gamma_{l s}=\frac{6 k_{l} \phi_{s} N u}{d_{s}^{2}}$,

271 and,

$272 \quad \gamma_{l g}=\frac{6 k_{l} \phi_{g} N u}{d_{g}{ }^{2}}$,

273 where $N u$ is the Nusselt number. To estimate $N u$, we used the empirical correlation proposed by Gunn 274 (1978), which depends on both the porosity and relative velocity between the phases. Since in our case 275 the relative velocities are very small because of the small amplitude of the perturbation and the 276 viscosity of the liquid, $N u$ may be expressed as a function of $\phi_{l}$ only:

$277 \quad N u=\left(7-10 \phi_{l}+5 \phi_{l}^{2}\right)$.

278

279

\section{II.5 Coupled phase model}

To compute the speed of sound from Eqs. (1-13), we employed the coupled phase theory (e.g.

281 Harker \& Temple 1988, Atkinson \& Kytömaa 1992, Evans \& Attenborough 1997, Valier-Brasier et al.

282 2015; see supplementary material 2, online, for details about the method and equations), which consists 
283 in imposing a small and monochromatic perturbation to all the variables that oscillate during the 284 propagation of the acoustic perturbation $\left(\rho_{l}, \rho_{s}, \rho_{g}, u, v, w, T_{l}, T_{s}, T_{g}, \phi_{l}, \phi_{s}, \phi_{g}, P\right)$ by using wave-like 285 solutions (here for the density of the liquid phase):

$286 \rho_{l}=\rho_{l}^{0}+\bar{\rho}_{l} e^{i(k x-\omega t)}$,

287 where $\rho_{l}^{0}$ is the static fluid density, $\bar{\rho}_{l}$ is the amplitude of the perturbation of the fluid density at the 288 source, and $i^{2}=-1$. Note that since all the phases are static and in thermal equilibrium before the 289 perturbation, $u_{0}=v_{0}=w_{0}=0$ and $T_{l}^{0}=T_{s}^{0}=T_{g}^{0}=T^{0}$. The exponential term in Eq. (32) expresses the spatial and 290 temporal variations of the liquid density and depends on $\omega$, the angular frequency $(\omega=2 \pi f, f$ is the 291 frequency of the perturbation), and $k$ the complex wavenumber defined as:

$292 k=\frac{\omega}{c}+i \alpha$,

293 where $c$ is the speed of sound and $\alpha$ is the associated intrinsic attenuation coefficient. After the 294 introduction of the oscillating variables and linearization (the products of two small oscillations are 295 neglected), the set of equations can be expressed as a matrix equation (see supplementary information 1 296 for details about the matrix equation):

$297 M\left[\bar{\rho}_{l}, \bar{\rho}_{s}, \bar{\rho}_{g}, \bar{\phi}_{l}, \bar{\phi}_{s}, \bar{\phi}_{g}, \bar{T}_{l}, \bar{T}_{s}, \bar{T}_{g}, \bar{u}, \bar{v}, \bar{W}, P\right]^{T}=0$

298 where $\boldsymbol{M}$ is a coefficients matrix containing $k$ as unique unknown. To ensure the equality in Eq (34), the 299 nontrivial solution (a perturbation exists) imposes that $\boldsymbol{M}$ can be inverted and thus:

$300 \operatorname{det}(\boldsymbol{M})=0$.

301 The speed of sound and associated attenuation coefficient at a given frequency can be found from the 302 wavenumber, $k$, that is physically meaningful and that satisfies Eq (35).

303

304

\section{II.6 Bounds of the sound speed in magmas}


The speed of sound in a suspension depends on the variation of its density and volume during 306 an adiabatic compression or dilatation (Temkin 1998). Let's consider an elementary volume, $V$, 307 containing a constant mass of solids and gas bubbles suspended in a viscous liquid. By neglecting the 308 relative motions between the phases, the suspension can be approximated as a homogeneous material 309 having a bulk density, $\rho^{*}$, defined as (Brennen 2005):

310

$$
\rho^{*}=\phi_{l} \rho_{l}+\phi_{s} \rho_{s}+\phi_{g} \rho_{g} \text {. }
$$

311 The total net change of the elementary volume, $d V$, can be written as the sum of the net changes of the 312 volume of the three phases:

$$
d V=d V_{l}+d V_{s}+d V_{g},
$$

314 where $d V_{l}$ is the net change of the volume of liquid, $d V_{s}$ is the net change of the volume of solid, and $315 d V_{g}$ is the net change of the volume of gas. Neglecting phase transformations, Eq. (37) may be 316 expressed as:

$317 \quad \frac{d \rho^{*}}{\rho^{*}}=\frac{\phi_{l}}{\rho_{l}} d \rho_{l}+\frac{\phi_{s}}{\rho_{s}} d \rho_{s}+\frac{\phi_{g}}{\rho_{g}} d \rho_{g}$,

318 where $d \rho *$ is the net change in the bulk density of the suspension, $d \rho_{l}$ is the net change of the liquid 319 density, $d \rho_{s}$ is the net change of the density of the solids, and $d \rho_{g}$ is the net change of the density of the 320 gas bubbles. The evolution of the density of each phase depends on the change in pressure (here we 321 consider that the pressure is the same in all the phases) and in its temperature as (here for a phase $i$ ):

$322 d \rho_{i}=\left(\frac{\partial \rho_{i}}{\partial P}\right)_{T} d P+\left(\frac{\partial \rho_{i}}{\partial T_{i}}\right)_{P} d T_{i}$,

323 where $\left(\partial \rho_{i} / \partial P\right)_{T}$ is the variation of the density of a constituent with the pressure at a constant 324 temperature, and $\left(\partial \rho_{i} / \partial T_{i}\right)_{P}$ is the derivative of its density with respect to its temperature at a constant 325 pressure. Introducing Eq. (39) into (38) yields: 
$326 \frac{d \rho^{*}}{\rho^{*}}=\frac{1}{K^{*}} d P+\frac{\phi_{l}}{\rho_{l}}\left(\frac{\partial \rho_{l}}{\partial T_{l}}\right)_{P} d T_{l}+\frac{\phi_{s}}{\rho_{s}}\left(\frac{\partial \rho_{s}}{\partial T_{s}}\right)_{P} d T_{S}+\frac{\phi_{g}}{\rho_{g}}\left(\frac{\partial \rho_{g}}{\partial T_{g}}\right)_{P} d T_{g}$,

327 where $K^{*}$ is the bulk modulus characterizing the suspension and defined as:

$328 \quad \frac{1}{K_{*}}=\frac{\phi_{1}}{K_{l}}+\frac{\phi_{s}}{K_{s}}+\frac{\phi_{g}}{K_{g}}$,

329 with $K_{l} / \rho_{l}=\left(\partial P / \partial \rho_{l}\right)_{T}, K_{s} / \rho_{s}=\left(\partial P / \partial \rho_{s}\right)_{T}$, and $K_{g} / \rho_{g}=\left(\partial P / \partial \rho_{g}\right)_{T}$. When the net changes in temperature of the 330 phases are neglected, the isothermal speed of sound is:

$331 \quad c^{-2}=\frac{d \rho^{*}}{d P}=\frac{\rho^{*}}{K^{*}}$.

When considering temperature variations, the speed of sound depends on the evolution of the

bulk density of the suspension with pressure at constant entropy (Temkin 2000, Rienstra \& Hirschberg

334 2004). The net change of entropy, $d S$, in each phase may be expressed as a function of the net change in

335 its temperature and pressure (here for a phase $i$ ):

336

$$
T_{i} d S_{i}=\left(\frac{\partial S_{i}}{\partial T_{i}}\right)_{P} d T_{i}+\left(\frac{\partial S_{i}}{\partial P}\right)_{T} d P
$$

337 Considering an isentropic transformation, Eq. (43) can be expressed as:

$$
\left(\frac{\partial T_{i}}{\partial P}\right)_{S}=-\left(\frac{\partial T_{i}}{\partial S_{i}}\right)_{P}\left(\frac{\partial S_{i}}{\partial P}\right)_{T}
$$

339 Because the magma constituents have different thermodynamic properties, the net changes in 340 temperature of the phases for the same net change in pressure are not equal. Two end-member scenarios 341 may be considered as a function of the perturbation frequency and characteristic times for the phases to 342 reach thermal equilibrium, $\tau$. When $f \gg \tau^{-1}$, the heat exchanges between the phases may be neglected 343 such that $d T_{l} \neq d T_{s} \neq d T_{g}$. Inserting Eq. (44) into Eq. (40) and considering the relationships 
$344 d T_{i}=\left(\partial T_{i} / \partial P\right)_{S} d P,\left(\partial T_{i} / \partial S_{i}\right)_{P}=T_{i} / C_{P i},\left(\partial S_{i} / \partial P\right)_{T}=-\alpha_{i} / \rho_{i}$, and $\left(\partial \rho_{i} / \partial T\right)_{P}=-\alpha_{i} \rho_{i}$, the speed of sound at

345 thermal disequilibrium reads:

$$
c^{-2}=\frac{d \rho^{*}}{d P}=\rho^{*}\left(\frac{1}{K^{*}}-\frac{\phi_{1} \alpha_{1}^{2} T^{0}}{C_{P I} \rho_{f}}-\frac{\phi_{s} \alpha_{s}^{2} T^{0}}{C_{P s} \rho_{s}}-\frac{\phi_{g} \alpha_{g}^{2} T^{0}}{C_{P g} \rho_{g}}\right)
$$

$$
d T^{*}=\frac{\phi_{l} \rho_{l} C_{P l} d T_{1}+\phi_{S} \rho_{S} C_{P_{S}} d T_{s}+\phi_{g} \rho_{g} C_{P g} d T_{g}}{\phi_{1} \rho_{l} C_{P l}+\phi_{S} \rho_{S} C_{P S}+\phi_{g} \rho_{g} C_{P g}} .
$$

351 Considering $d T_{l}=d T_{s}=d T_{g}=d T^{*}$ into Eq. (40) and inserting Eqs. (44) and (46) gives the following

352 relationship for the speed of sound at thermal equilibrium:

353

$$
c^{-2}=\frac{d \rho^{*}}{d P}=\frac{\rho^{*}}{K^{*}}-\frac{\alpha^{* 2} T^{0}}{C_{P}^{*}}
$$

354 where $\alpha^{*}$ is the bulk coefficient of thermal expansion defined as:

$$
\alpha^{*}=\phi_{l} \alpha_{l}+\phi_{s} \alpha_{s}+\phi_{g} \alpha_{g}
$$

and $C_{P} *$ is the specific bulk heat capacity at constant pressure calculated as the mass average (:

$$
C_{P} *=\frac{\phi_{1} \rho_{l} C_{P l}+\phi_{s} \rho_{S} C_{P S}+\phi_{g} \rho_{g} C_{P g}}{\rho_{*}}
$$

The characteristic time at which the transition between the two regimes occurs depends on the rate at which the heat is exchanged between the phases. Two characteristic times may be calculated since both the gas and solids are suspended in the liquid. To estimate these critical frequencies, we start

361 by considering a static suspension of gas bubbles in a liquid. The evolution of the difference in 362 temperature between the two phases resulting only from the heat exchanged between them may be 363 approximated as: 
365 where $\tau_{g}$ is the characteristic time to equilibrate the temperature of the liquid and the gas phases given 366 by:

$$
\tau_{g}^{-1}=\gamma_{l g}\left(\frac{1}{\phi_{l} \rho_{l} C_{P l}}+\frac{1}{\phi_{g} \rho_{g} C_{P g}}\right) .
$$

368 Similarly, the characteristic time to equilibrate the temperature of the phases in a suspension of solids

369 in a liquid, $\tau_{s}$, is:

$$
\tau_{s}^{-1}=\gamma_{l s}\left(\frac{1}{\phi_{l} \rho_{l} C_{P f}}+\frac{1}{\phi_{S} \rho_{S} C_{P S}}\right)
$$

\section{II.7 Magma under considerations}

We considered three different magmas representative of compositions that may be encountered in

374 arc magmatism (basalt, andesite, and dacite) and simulated their adiabatic cooling and crystallization

375 using the software MELTS (Ghiorso 2004) at a pressure of $150 \mathrm{MPa}$ using the Ni-NiO oxygen buffer

376 for the andesite and dacite, and the quartz-fayalite-magnetite buffer for the basalt. The initial

377 compositions were taken from Dufek \& Bachmann (2010) and Martel et al. (1999) (see Table 1). We

378 set the initial amounts of dissolved water in the magmas to $\sim 3.5 \mathrm{wt} \%$ to ensure that water vapor starts

379 exsolving once the mass fraction in liquid is $\sim 70 \mathrm{wt} \%$ (Duan 2014). We used the thermodynamic

380 properties of each phase computed during the cooling simulations to estimate the speed of sound in the magmas as a function of their temperature. All the simulations were stopped when the crystallinity of

382 the magmas reached the maximum packing fraction $\left(\phi_{l}=0.36\right)$. 


\section{Results}

\section{III.1 The speed of sound in 3 phases suspensions}

To illustrate how the material properties and characteristics of the perturbation affect the speed of sound in magmas, we define reference conditions relevant to magmas (Table 2) and vary selected parameters independently from each other. Figure 3A displays the evolution of the velocity of a compressional wave as a function of the volume fraction in liquid, solids, and gas bubbles when $f=0.01$ Hz. It shows that the speed of sound decreases rapidly once a small volume fraction of volatiles is exsolved. When $\phi_{g}>0.05$, the solid volume fraction has a negligible influence on the compressional wave velocity compared to that in the presence of gas.

Figure $3 \mathrm{~B}$ displays the speed of sound in the same suspension as in Fig. 3A when $f=100 \mathrm{~Hz}$. Results show the same dependence of the wave velocity on $\phi_{g}$. The amplitude of the decrease of the speed of sound for the same volume fraction of gas is, however, slightly lower as illustrated by the shift of the position of the isocontour of $c=500 \mathrm{~m} \mathrm{~s}^{-1}$. The frequency of the perturbation changes both the minimum $\left(c \approx 457 \mathrm{~m} \mathrm{~s}^{-1}\right.$ when $f=0.01 \mathrm{~Hz}$ and $c \approx 482 \mathrm{~m} \mathrm{~s}^{-1}$ when $\left.f=100 \mathrm{~Hz}\right)$ and maximum $(c \approx 3117$ $\mathrm{m} \mathrm{s}^{-1}$ when $f=0.01 \mathrm{~Hz}$ and $c \approx 3150 \mathrm{~m} \mathrm{~s}^{-1}$ when $f=100 \mathrm{~Hz}$ ) velocities computed by the model. On the contrary, when $\phi_{l}=1$ the speed of sound is the same at the two frequencies $\left(2582 \mathrm{~m} \mathrm{~s}^{-1}\right)$.

To further investigate the influence of the perturbation frequency on sound speed in a magma, we set the volume fractions of its constituents to $\phi_{l}=0.65, \phi_{s}=0.3$, and $\phi_{g}=0.05$ and calculate the dispersion curve of the acoustic waves (Fig. 4). Results show that the speed of sound increases nonlinearly with the frequency and that three plateaux can be identified. The lowest plateau at $c \approx 1020 \mathrm{~m}$ $\mathrm{s}^{-1}$ occurs when $f<0.01 \mathrm{~Hz}$. The second velocity plateau at $c \approx 1025 \mathrm{~m} \mathrm{~s}^{-1}$ occurs when $0.1 \mathrm{~Hz}<f<1$ Hz whereas the third and fastest one at $c \approx 1090 \mathrm{~m} \mathrm{~s}^{-1}$ is reached when $f>100 \mathrm{~Hz}$. As illustrated in Fig. 4, the uppermost plateau occurs when $f \gg \max \left(\tau_{s}^{-1}, \tau_{g}^{-1}\right)$ and corresponds to the thermal disequilibrium 
407 bound of the speed of sound predicted by Eq. (38). The lowest plateau is found when $f \gg \min \left(\tau_{s}^{-1}, \tau_{g}^{-1}\right)$ 408 and corresponds to thermal equilibrium bound of the speed of sound given by Eq. (40). The isothermal 409 bound (Eq. 35) underestimate the speed of sound at all frequencies.

410 Figure 5 displays the evolution of the wave velocity as a function of the propagation angle, $\theta$, and 411 frequency of the perturbation. When $f \geq 0.1 \mathrm{~Hz}$, the velocity of the wave is lower when the wave 412 propagates upward than when it propagates downward. When $f<0.1 \mathrm{~Hz}$, the speed of sound show a 413 complex dependence on the propagation angle. The maximum velocity is computed when $\theta=\pi / 2$ 414 whereas the minimum sound speed occurs when the wave propagates downward with a propagation 415 angle of $\sim 30^{\circ}$ from the horizontal. The propagation angle influences sound speed because of the terms 416 involving the gravitational acceleration in Eqs. (4-9). In momentum conservation, these terms express 417 the contribution of the change in the density of the phases to the gravitational force. In the energy 418 conservations, the term involving the gravitational acceleration express the rate at which the potential 419 energy change as a function of the velocity of the phase along the vertical direction. The amplitude of 420 the differences in the wave velocity as a function of the propagation angle $(<1 \%)$ is negligible 421 compared to the influence of the volume fraction of the constituents (Fig. 3) and frequency of the 422 perturbation (Fig. 4).

423 Figure 5A displays the difference between the speed of sound computed when lubrication is 424 accounted for and when it is neglected as a function of the ratio $\phi_{s} / \phi_{s} \max$ and perturbation frequency. 425 The difference when the influence of lubrication forces increases with the ratio $\phi_{s} / \phi_{s \max }$ and with wave 426 frequency. When $f<10^{3} \mathrm{~Hz}$, neglecting lubrication forces results in a negligible underestimation of the 427 speed of sound $\left(<10^{-4} \mathrm{~m} \mathrm{~s}^{-1}\right)$. 


\section{III.2 Application to magmas}

431 Figure 6A-E displays the evolution of the phase assemblages and thermodynamic properties of the

432 three magmas computed by the cooling simulations and averaged over the phases with Eq. (29), (34),

433 (41), and (42) (see supplementary material 3, online, for details on the thermodynamic properties of the

434 constituents). The thermodynamic properties show sharp changes once the water vapor is exsolved. The

435 bulk moduli of the magmas, in particular, drop by almost one order of magnitude once a small fraction

436 of water is exsolved (Fig. 6D), resulting in a sharp decrease of the sound speed (Fig 6F). In the absence

437 of gas, the influence of the frequency of the perturbation is weak enough for the lower (Eq. 40) and

438 upper (Eq. 38) bounds of the sound speed to be almost equal. On the contrary, the two bounds show

439 significant differences when a gas phase is present (Fig. 6F). The amplitude of the difference between

440 the two bounds increases with the volume fraction of gas and decreases with the temperature. In the

441 final phases assemblages, the gas volume fractions are $\phi_{g} \approx 0.15$ in the basalt (Fig $6 \mathrm{~A}$ ), $\phi_{g} \approx 0.1$ in the 442 andesite (Fig. 6B), and $\phi_{g} \approx 0.05$ in the dacite (Fig. 6C). These values translate into amplitude

443 differences between the upper and lower bounds of $\sim 150 \mathrm{~m} \mathrm{~s}^{-1}$ in the basalt, $\sim 200 \mathrm{~m} \mathrm{~s}^{-1}$ in the andesite, 444 and $\sim 250 \mathrm{~m} \mathrm{~s}^{-1}$ in the dacite (Fig 6F).

445

446 


\section{Discussion}

\section{IV.1 Predicting the speed of sound in magmas}

Several relationships have been proposed to estimate the speed of sound in two-phase suspensions (e.g. Kuster \& Toksöz 1974, Kieffer 1977, Berryman 1980, Harker \& Temple 1988, Commander \& Prosperetti 1989, Atkinson \& Kytömaa 1992), and employed for bubbly magmas (e.g. Chouet 1996, Kumagai \& Chouet 2000, Morrissey \& Chouet 2001, Neuberg \& O’Gorman 2002, Karlstrom \& Dunham 2016). To compare all these models with the results of Eq. (28) based on the coupled phase theory, we considered a suspension of bubbles of an ideal gas suspended in water (see Table 3 for thermodynamic properties of the phases). Figure 6A displays the comparison of the speed of sound estimated with the different models for $10^{-3} \leq f \leq 10^{3} \mathrm{~Hz}$. The models neglecting the evolution of the temperature of the phases (Kuster \& Toksöz 1974, Berryman 1980, Harker \& Temple 1988, Atkinson \& Kytömaa 1992, Neuberg \& O’Gorman 2002, Karlstrom \& Dunham 2016) give the same results as Eq. (35) and underestimate the speed of sound and do not capture its dispersion (Fig. 6A). When a material is compressed or decompressed, the temperature of its constituents changes accordingly, inducing their thermal expansions, which oppose the change of volume resulting from the change in pressure. As a result, neglecting the thermal effects results in overestimating the ratio $\left(d \rho^{*} / d P\right)$, and in turn, underestimating the speed of sound. In magmas and at low frequency, the difference between the isothermal and isentropic speed of sounds is, however, small when a gas phase is present (Fig. 6F). Neglecting the evolution of the temperature of the phases is thus an acceptable assumption for bubbly magmas at low frequencies $\left(f<\sim 10^{-2} \mathrm{~Hz}\right.$ in Fig. 4) given the uncertainty on the thermodynamic properties of the constituents. At higher frequencies, the isothermal assumption results in a large underestimation of the speed of sound in a bubbly magma (of $\sim 200 \mathrm{~m} \mathrm{~s}^{-1}$ in andesite with $\phi_{g} \approx 0.10$; Fig $5 \mathrm{~F}$ ). On the contrary, in the absence of exsolved volatiles, the isothermal assumption 
470 results in a significant underestimation of the speed of sound compared with the isentropic case at any

471 frequency (of $\sim 50 \mathrm{~m} \mathrm{~s}^{-1}$ in Fig. $6 \mathrm{~F}$ ).

472 Other relationships account for the thermal effects during the propagation of an acoustic wave.

473 The model proposed by Kieffer (1977) predicts sound speeds between the upper and lower bounds but 474 does not capture the dispersion of the sound (Fig. 7A). In this model, while the temperature changes are 475 accounted for in the gas phase, they are neglected in the liquid. As a result, the compression and 476 decompression are isentropic in the gas while isothermal in the liquid, which explains why this model 477 predicts speed of sounds between those predicted with Eqs. (42) and (45). The lack of sound dispersion 478 results from the absence of heat exchange between the phases in the model. The dispersion of sound is 479 particularly important in bubbly magmas (Fig. 3 and Fig. 6F). In general, $\alpha_{g} /\left(\rho_{g} C_{p g}\right) \gg \alpha_{l} /\left(\rho_{l} C_{p l}\right)$. As a 480 result, for the same net change in pressure $\left|d T_{l}\right|<\left|d T^{*}\right|<\left|d T_{g}\right|$. Since $\alpha_{g} \gg \alpha_{f}$ the amplitude of the thermal 481 expansion of the gas bubbles increases significantly out of thermal equilibrium, which in turn amplifies 482 the resistance of bulk material to compression and decompression and increases the speed of sound 483 (Temkin 2000). This effect results in the two increases of the speed of sound with frequency observed 484 in Fig. 4. The first increase occurs when the solids become out of thermal equilibrium with the liquid. 485 This velocity jump may be ignored in crystal-bearing magmas (Fig 6F) because the coefficients of 486 thermal expansion of the melt and crystals are smalls (see supplementary material 3, online). The relationship proposed by Commander \& Prosperetti (1989) and employed by Chouet 488 (1996), Kumagai \& Chouet (2000) and Morrissey \& Chouet (2001) accounts for the exchange of heat 489 from the bubbles to the liquid and captures the increase of the speed of sound at the same range of 490 frequencies as Eq. (28) (Fig. 6A). The evolution of the temperature in the liquid is, however, neglected 491 in this model. Consequently, it predicts sound speeds slower than Eq. (28) for all the frequencies. This 492 model also considers the dynamics of the interface between the gas bubbles and surrounding liquid, a 
493 phenomenon not accounted for in our model. The dynamics of the bubbles are expected to cause a 494 sudden increase in sound speed at a resonance frequency (Commander \& Prosperetti 1989, Chouet 495 1996), which is not captured in Eq. (28) (Fig 7B). In magmas, the resonance frequency of bubbles is on 496 the order of the $\mathrm{kHz}$ (Chouet 1996). This is above the frequencies usually used in geophysics and can 497 be ignored for most applications.

498 It should be noted that another increase in the speed of sound is expected for each discrete 499 phase at higher frequencies than explored herein (Temkin 2000). These velocity jumps result from the 500 translational relative motions between the liquid and the discrete phases. As for heat, the constituents of 501 the suspension exchange momentum during the propagation of an acoustic perturbation because of 502 their relative motions. The rates of momentum transfer in the suspension depend on the coefficients of 503 momentum exchange given by Eqs. (16-17). The evolution of the relative velocity between the carrier 504 and suspended phases is (here between the liquid and the gas):

$505 \partial_{t}(u-w)+v_{l g}(u-W)=0$

506 where $v_{l g}$ is the critical frequency above which translational effect cannot be neglected. It is defined as 507 the inverse of the characteristic time needed for the relative velocity between the gas and liquid phases 508 to vanish:

$509 \quad v_{l g}=\beta_{l g}\left(\frac{1}{\phi_{l} \rho_{l}}+\frac{1}{\phi_{g} \rho_{g}}\right)$

510 Similarly, the critical frequency for translational relative motion between the solids and liquid, $v_{l s}$, is:

$511 \quad v_{l g}=\beta_{l s}\left(\frac{1}{\phi_{l} \rho_{l}}+\frac{1}{\phi_{s} \rho_{s}}\right)$

512 When $f>\max \left(v_{l s}, v_{l g}\right)$ the magnitude of the relative velocity between the carrier liquid and discrete 513 phases becomes significant and cannot be ignored when computing the speed of sound in the 
514 suspension. At these frequencies, the assumption of homogeneity required to express Eq. (29) is

515 violated such that Eq. (38) cannot be employed to estimate the velocity of compressional waves. The

516 relative motions between the phases cause the increase in the speed of sound predicted by Eq. (28)

517 observed in Fig. 6B. The critical frequency for translational effects is inversely proportional to the

518 dynamic viscosity of the liquid phases. For magmas, $v_{l g}$ and $v_{l s}$ are far above $(>1 \mathrm{MHz})$ the maximum

519 frequencies considered here and used in geophysics. The influence of the translational relative motions

520 on the speed of sound can thus be safely neglected in magmas for most applications.

\section{IV.2 Limit of validity of the model}

In a suspension, the initiation of interactions between the discrete particles marks the onset of

rigidity and the transition from liquid-like to solid-like elastic body. In our model, while contacts are

neglected, we accounted for the exchange of momentum between neighboring crystals through

lubrication forces. The initiation of lubricated interactions between neighboring particles has been used in geophysics, $\sim 10^{-9}<\eta k^{2} / \rho_{s}<\sim 10^{1}$, such that the influence of lubrication on the speed of sound is negligible (Fig. 5B). As a result, the initiation of contact between the crystals is associated with the onset of rigidity in magmas and is expected to result in the sharp increase of the velocity of the compressional waves and the emergence of shear waves (Caricchi et al. 2008). The volume fraction at

535 which a continuous contact network form (at random loose packing) in a magma depends on the sizes,

536 shapes, orientations, and roughnesses of the crystals such that it can be significantly larger than 
$537 \phi \approx 0.36$, which corresponds to the minimum random close packing calculated for frictionless and

538 monodisperse spheres (Bergantz et al. 2017). The difference between random loose and close packings

539 is expressed in the coordination numbers (average number of particle-particle contacts per particle),

540 which is larger at random close packing than at random loose packing. The transition between the two

541 packings occurs as a consequence of the reorganization of the crystal network due to contact sliding

542 and particle non-affine motions. The increase in the coordination number raises the rigidity of the

543 suspension and the speed of sound. Thus the rigidity modulus is expected to increase progressively

544 with the decreases of $\phi_{f}$ between the random loose and close packings. Since the influence of the

545 contact between the solids is beyond the scope of our model, the initiation of a fragile contact network

546 (Bergantz et al. 2017) between the crystals at magma/mush transition represents the limit of its

547 applicability. Contacts between solids are implicitly accounted for in the effective medium theory (e.g.

548 Kuster \& Toksöz 1974, Berryman 1980) and the Hertz-Mindlin contact theory. In dense suspensions

549 where solids are in cohesionless contact, the bulk and rigidity moduli also depend on the confining

550 pressure and amplitude of the perturbation, which affects the non-affine motions of the grains, contact

551 slidings, and shear dilatancy (e.g. Makse et al. 2004, Brum et al. 2019). Such phenomena may induce

552 either strengthening or weakening of the rigidity of the suspension because of the change in the contact

553 network (Van den Wildenberg et al. 2013). The effective medium theory is not able to account for the

554 relaxations associated with changes in the contact network and usually overestimates the shear modulus

555 (Makse et al. 2004). As a result, the applicability of methods based on the effective medium theory to

556 compute the speed of sound between the random loose and random close packing is uncertain given the

557 proneness of the crystal network to structural reordering and non-affine motions.

558 In addition to the absence of contact between particles, we made assumptions when deriving the

559 conservation equations that may affect sound speed. We neglected the mass transfers associated with 
560 the precipitation or melting of crystals and the growth, dissolution, or nucleation of gas bubbles. The

561 importance of the mass transfers on the acoustic properties of a suspension depends on the rates of

562 mass exchange between the constituents (Fuster \& Montel 2015). In magmas, the exsolution or

563 dissolution of the volatiles depends on the changes in their solubility in the melt phase, which is mainly

564 controlled by the pressure changes. The nucleation of bubbles is expected to occur during a short

565 period (Toramaru 1995) and requires a large supersaturation pressure (>5 Mpa) even in the presence of

566 crystals (Hurwitz \& Navon 1994, Shea 2017). In our model, we considered small perturbations and the

567 magma being initially at thermodynamic equilibrium (no steady mass or heat transfers). Thereby, the

568 small amplitudes of the perturbations in pressure are not expected to trigger the nucleation of bubbles,

569 which requires large amplitude waves (Rothery et al. 2007). The rate of the exchange of mass between

570 the dissolved and exsolved volatiles is controlled by the bubbles sizes and the diffusion coefficient of

571 the volatiles species in the melt phase (Toramaru 1995). The competition between diffusion and the rate

572 of pressure change can be measured by the ratio of the diffusive time scale over the decompression

573 time scale (Lensky et al. 2004). The diffusivity coefficient of water (the most common volatile in

574 magma) is low (between $\sim 10^{-13}$ and $\sim 10^{-10} \mathrm{~m}^{2} \mathrm{~s}^{-1}$; Zhang \& Behrens 2000) so that mass transfer between

575 the melt and gas phases is negligible (i.e. the diffusive ratio is $>1$ ) when changes in pressure are faster

576 than $\sim 0.01-0.0001 \mathrm{~Hz}$ for bubbles of $10-100 \mu \mathrm{m}$ in radius, respectively. Similarly, the rates of the

577 precipitation or melting of the crystals in magmas are small (e.g. $\sim 10^{-13}$ and $10^{-12} \mathrm{~m} \mathrm{~s}^{-1}$ for crystal

578 growth; Hawkesworth et al. 2004) so that we do not expect the mass transfer between the liquid and

579 solid phases to have a significant influence on the velocity of a compressional wave in magma.

580 Heat and mass exchanges between the phases are controlled by the coupling terms $\left(\beta_{l s}, \beta_{l g}, \gamma_{l s}\right.$,

581 and $\gamma_{l g}$ ), which are based on empirical correlations. The choice for the correlations employed to 582 calculate the coefficients of momentum exchange, $\beta_{l s}$ and $\beta_{l g}$, influences the two critical frequencies, $v_{l s}$ 
583 and $v_{l g}$, at which the translational relative velocities between the suspended and carrier phases start to

584 significantly influence sound speed (when $f>10^{5} \mathrm{~Hz}$ in Fig. 8B). Here we considered the creeping and

585 steady flow of the liquid around the discrete phases because of the dynamic viscosity of the melt

586 allowing us to neglect inertial and unsteady terms. We employed a Stokes law for high porosity $\left(\phi_{l}>\right.$

$587 \sim 0.893$ ) as usually used in the coupled phase theory (e.g. Harker \& Temple 1988, Atkinson \& Kytömaa

588 1992, Evans \& Attenborough 1997). For lower porosity $\left(\phi_{l}<\sim 0.893\right)$, we used a Kozeny-Carman

589 relationship instead of the Stokes law to account for the influence of the presence of the surrounding

590 crystals and the associated decrease in permeability. The maximum difference between the momentum

591 exchanges coefficients predicted by the Stokes and Kozeny-Carman relationships occurs at the

592 maximum packing fraction and reaches $\sim 1$ order of magnitude. Therefore, account for the Stokes law

593 instead of the Kozeny-Carman law would result in a decrease of the critical frequencies, $\beta_{l s}$ and $\beta_{l g}$, of

$594 \sim 1$ order of magnitude at maximum. The two critical frequencies, $\beta_{l s}$ and $\beta_{l g}$, calculated considering a

595 Stokes law remain above the range of frequency considered $\left(10^{-3}-10^{3} \mathrm{~Hz}\right)$. As a result, in the range of

596 the frequency considered here, the choice of the law for the exchange of momentum has a negligible

597 influence on the calculated speed of sound in magma.

598 Similarly, the choice of the empirical relationship employed to predict Nusselt number in the

599 coefficient of heat transfer between the phases, $\gamma_{l s}$ and $\gamma_{l g}$, impacts the critical frequencies at which the

600 transition between thermal equilibrium and disequilibrium regimes occurs. We used the correlation

601 proposed by Gunn (1978) to obtain an expression depending on the porosity of the suspension. This

602 expression also accounts for the influence of the relative velocity between the carrier and suspended

603 phases. We showed that within the range of frequency considered, the relative velocity between the

604 constituents is negligible. As a result, the influence of the relative motion between the constituents on

605 the rates of heat exchange is weak and can be neglected. Furthermore, other empirical relationships 
606 predicting the Nusselt number exist (e.g. Ranz, 1952; Li \& Mason, 2000) but often reduce to $N u=2$ in

607 the absence of relative flow between the constituents, which is the same $N u$ as predicted by Eq. (31)

608 when $\phi_{l}=1$. At the minimum porosity $\left(\phi_{l}=0.36\right)$, Eq. (31) predicts $N u=\sim 4$. As a result, employing

609 another empirical correlation to calculate the Nusselt number will tend to decrease the two critical

610 frequencies, $\tau_{g}^{-1}$ and $\tau_{g}^{-1}$, by a factor of 2 at maximum. The two theoretical maximum and minimum

611 wave velocities (Eqs. 45 and 47) remain unchanged since the correlation of the Nusselt number only

612 affects the rate of the heat exchanges but not the equilibrium temperature predicted by Eq. (46).

613

\section{IV.3 Implication in volcanology:}

615 Our results have implications for the interpretation of seismic signals recorded around 616 volcanoes. Long Period (LP) signals are thought to result from the radiation from the acoustic 617 excitation of the magma located in cracks (e.g. Chouet 1986; Kumagai \& Chouet 2000) or in the 618 volcanic conduit (e.g. Jousset et al. 2003; Jousset et al. 2004) with the surrounding solid rock. The 619 velocity of compression waves in the magma located in the cracks or conduit affects the resonance 620 frequency, radiation attenuation, and delay between two successive LP events. The presence of 621 exsolved volatiles in magma induces that compressional waves propagate faster at high frequency $622(>100 \mathrm{~Hz})$ than low frequency $(<1 \mathrm{~Hz})$. Consequently, the resonance frequency of a crack filled with 623 bubbly magma will be higher, and the radiation attenuation lower, at a high frequency than at a low 624 one. In the context of a volcanic conduit, the higher velocity of the wave at high frequency translates to 625 the decrease of the delay between two successive LP events and an increase in their frequency.

626 The detection of exsolved volatiles and estimation of their volume fraction in magma is 627 important to assess volcanic hazards. Tomography images of seismic waves velocity are an interesting 628 tool to map compositional changes in magma reservoirs. The speed of sound in magma depends on the 
629 crystal and exsolved volatiles content. Crystals increase the velocity of compressional waves but 630 weakly affect the dispersion of sound in the magma. The presence of gas bubble greatly decrease and 631 induces the dispersion of sound. The difference between the speed of sound at high and low frequencies 632 is proportional to the gas volume fraction. Consequently, the comparison of tomography images 633 computed for different frequencies at low and high frequencies might help in highlighting the presence 634 of gas and in mapping magma reservoirs. 


\section{V. Conclusion}

636 We developed an analytical model to estimate the speed of sound in magmas consisting of a 637 suspension of solids and/or gas bubbles in a viscous liquid. Our model shows that the velocity of 638 compressional waves in a magma varies non-linearly with frequency between two asymptotic bounds.

639 These two bounds correspond to the speed of sound when all the constituents of the magma are in

640 thermal equilibrium (lower bound) and when the heat exchanges between the phases are neglected 641 (upper bound). We then simulated the cooling of three magmas representative of the diversity of 642 compositions that may be encountered in arc magmatism and applied our model to calculate the speed 643 of sound. Results show that the presence of gas in a magma yields a sharp decrease in the velocity of 644 sound and enhances significantly its dispersion. We found that the exchanges of heat between the 645 constituents may be neglected in crystal-bearing magmas, but that they cannot be ignored once a gas 646 phase is present. Finally, we compared the speed of sound predicted by our model to the results of other 647 relationships usually used by authors for magmas in the range $10^{-3}-10^{3} \mathrm{~Hz}$. The difference between our 648 modeled of the velocity of compressional acoustic waves and literature values results from the 649 simplifications and assumptions made when considering the evolution of the temperature of the phases 650 and the heat exchanges. These differences typically range from 0.5 to $8 \%$ and are largest at frequencies $651>10 \mathrm{~Hz}$. 


\section{Acknowledgment:}

653 AC was supported by the National Science Foundation grant EAR-1950113. CA was supported by the 654 European Unions's Horizon 2020 research and innovation programme under the Marie Sklodowska655 Curie grant agreement No. 794594. GWB was supported by National Science Foundation grants DGE656 1256068, EAR-1447266, EAR-1950113. The authors thank Juan Carlos Afonso and an anonymous 657 reviewer for their reviews that improved this manuscrip and Lapo Boschi for his editorial handling. 658

659 Data Availability:

660 All the data and code related to this manuscript are available in the supplementary materials (online). 661 
Annen, C., Blundy, J.D., Leuthold, J. \& Sparks, R.S.J. (2015) Construction and evolution of igneous bodies: Towards an integrated perspective of crustal magmatism. Lithos, 230, 206-221. doi:10.1016/j.lithos.2015.05.008

Atkinson, C.M. \& Kytömaa, H.K. (1992) Acoustic wave speed and attenuation in suspensions. International Journal of multiphase flow, 18, 577-592, Elsevier.

Bachmann, O. \& Bergantz, G.W. (2004) On the origin of crystal-poor rhyolites: extracted from batholithic crystal mushes. Journal of Petrology, 45, 1565-1582, Oxford University Press. Bachmann, O. \& Huber, C. (2019) The inner workings of crustal distillation columns; the physical mechanisms and rates controlling phase separation in silicic magma reservoirs. Journal of Petrology, 60, 3-18, Oxford University Press.

Benyahia, S., Syamlal, M. \& O’Brien, T.J. (2006) Extension of Hill-Koch-Ladd drag correlation over all ranges of Reynolds number and solids volume fraction. Powder Technology, 162, 166-174, Elsevier.

Bergantz, G.W., Schleicher, J.M. \& Burgisser, A. (2017) On the kinematics and dynamics of crystalrich systems. Journal of Geophysical Research: Solid Earth, 122, 6131-6159. doi:https://doi.org/10.1002/2017JB014218

Berryman, J.G. (1980) Long-wavelength propagation in composite elastic media I. Spherical inclusions. The Journal of the Acoustical Society of America, 68, 1809-1819, Acoustical Society of America.

Brennen, C.E. (2005) Fundamentals of Multiphase Flow, Cambridge University Press.

Brum, J., Gennisson, J.L., Fink, M., Tourin, A. \& Jia, X. (2019) Drastic slowdown of the Rayleigh-like wave in unjammed granular suspensions. Physical Review E, 99, 042902, APS. 
Carcione, J.M., Farina, B., Poletto, F., Qadrouh, A.N. \& Cheng, W. (2020) Seismic attenuation in partially molten rocks. Physics of the Earth and Planetary Interiors, 309, 106568. doi:10.1016/j.pepi.2020.106568

Caricchi, L., Annen, C., Blundy, J., Simpson, G. \& Pinel, V. (2014) Frequency and magnitude of volcanic eruptions controlled by magma injection and buoyancy. Nature Geoscience, 7, 126130, Nature Publishing Group. doi:10.1038/ngeo2041

Caricchi, L., Burlini, L. \& Ulmer, P. (2008) Propagation of P and S-waves in magmas with different crystal contents: Insights into the crystallinity of magmatic reservoirs. Journal of Volcanology and Geothermal Research, 178, 740-750, Elsevier.

Caricchi, L., Burlini, L., Ulmer, P., Gerya, T., Vassalli, M. \& Papale, P. (2007) Non-Newtonian rheology of crystal-bearing magmas and implications for magma ascent dynamics. Earth and Planetary Science Letters, 264, 402-419, Elsevier.

Carrara, A., Burgisser, A. \& Bergantz, G.W. (2019) Lubrication effects on magmatic mush dynamics. Journal of Volcanology and Geothermal Research, 380, 19-30, Elsevier.

Carrara, A., Burgisser, A. \& Bergantz, G.W. (2020) The architecture of intrusions in magmatic mush. Earth and Planetary Science Letters, 549, 116539. doi:10.1016/j.epsl.2020.116539

Cassidy, M., Manga, M., Cashman, K. \& Bachmann, O. (2018) Controls on explosive-effusive volcanic eruption styles. Nature Communications, 9, 1-16, Nature Publishing Group.

Chouet, B. (1986) Dynamics of a fluid-driven crack in three dimensions by the finite difference method. Journal of Geophysical Research: Solid Earth, 91, 13967-13992. doi:10.1029/JB091iB14p13967

Chouet, B.A. (1996) New Methods and Future Trends in Seismological Volcano Monitoring. in Monitoring and Mitigation of Volcano Hazards eds. Scarpa, R. \& Tilling, R.I., pp. 23-97, Berlin, Heidelberg: Springer. doi:10.1007/978-3-642-80087-0_2 
Collier, L., Neuberg, J.W., Lensky, N., Lyakhovsky, V. \& Navon, O. (2006) Attenuation in gas-charged magma. Journal of volcanology and geothermal research, 153, 21-36, Elsevier.

Commander, K.W. \& Prosperetti, A. (1989) Linear pressure waves in bubbly liquids: Comparison between theory and experiments. The Journal of the Acoustical Society of America, 85, 732746, Acoustical Society of America. doi:10.1121/1.397599

De Siena, L., Thomas, C., Waite, G.P., Moran, S.C. \& Klemme, S. (2014) Attenuation and scattering tomography of the deep plumbing system of Mount St. Helens. Journal of Geophysical Research: Solid Earth, 119, 8223-8238, Wiley Online Library.

Degruyter, W., Parmigiani, A., Huber, C. \& Bachmann, O. (2019) How do volatiles escape their shallow magmatic hearth? Philosophical Transactions of the Royal Society A, 377, 20180017, The Royal Society Publishing.

Delph, J.R., Ward, K.M., Zandt, G., Ducea, M.N. \& Beck, S.L. (2017) Imaging a magma plumbing system from MASH zone to magma reservoir. Earth and Planetary Science Letters, 457, 313324. doi:10.1016/j.epsl.2016.10.008

Dingwell, D.B. \& Webb, S.L. (1989) Structural relaxation in silicate melts and non-Newtonian melt rheology in geologic processes. Physics and Chemistry of Minerals, 16, 508-516, Springer.

Duan, X. (2014) A general model for predicting the solubility behavior of H2O-CO2 fluids in silicate melts over a wide range of pressure, temperature and compositions. Geochimica et Cosmochimica Acta, 125, 582-609. doi:10.1016/j.gca.2013.10.018

Dufek, J. \& Bachmann, O. (2010) Quantum magmatism: Magmatic compositional gaps generated by melt-crystal dynamics. Geology, 38, 687-690, Geological Society of America.

Eichelberger, J. \& Izbekov, P. (2000) Eruption of andesite triggered by dyke injection: contrasting cases at Karymsky Volcano, Kamchatka and Mt Katmai, Alaska. Philosophical Transactions of the Royal Society of London. Series A: Mathematical, Physical and Engineering Sciences. doi:10.1098/rsta.2000.0599 
Ergun, S. (1952) Fluid flow through packed columns. Chem. Eng. Prog., 48, 89-94.

Esquivel-Sirvent, R., Green, D.H. \& Yun, S.S. (1995) Critical mechanical behavior in the fluid/solid transition of suspensions. Applied Physics Letters, 67, 3087-3089, American Institute of Physics.

Evans, J.M. \& Attenborough, K. (1997) Coupled phase theory for sound propagation in emulsions. The Journal of the Acoustical Society of America, 102, 278-282, Acoustical Society of America. doi:10.1121/1.419745

Fuster, D. \& Montel, F. (2015) Mass transfer effects on linear wave propagation in diluted bubbly liquids. Journal of Fluid Mechanics, 779, 598-621, Cambridge University Press.

Ghiorso, M.S. (2004) An equation of state for silicate melts. I. Formulation of a general model. American Journal of Science, 304, 637-678, American Journal of Science.

Gidaspow, D. (1994) Multiphase flow and fluidization: continuum and kinetic theory descriptions, Academic press.

Gumerov, N.A., Ivandaev, A.I. \& Nigmatulin, R.I. (1988) Sound waves in monodisperse gas-particle or vapour-droplet mixtures. Journal of Fluid Mechanics, 193, 53-74, Cambridge University Press.

Gunn, D.J. (1978) Transfer of heat or mass to particles in fixed and fluidised beds. International Journal of Heat and Mass Transfer, 21, 467-476, Elsevier.

Hammond, W.C. \& Humphreys, E.D. (2000) Upper mantle seismic wave attenuation: Effects of realistic partial melt distribution. Journal of Geophysical Research: Solid Earth, 105, 1098710999, Wiley Online Library.

Harker, A.H. \& Temple, J.A.G. (1988) Velocity and attenuation of ultrasound in suspensions of particles in fluids. Journal of Physics D: Applied Physics, 21, 1576, IOP Publishing.

Hawkesworth, C., George, R., Turner, S. \& Zellmer, G. (2004) Time scales of magmatic processes. Earth and Planetary Science Letters, 218, 1-16. doi:10.1016/S0012-821X(03)00634-4 
Hier-Majumder, S. (2008) Influence of contiguity on seismic velocities of partially molten aggregates. Journal of Geophysical Research: Solid Earth, 113, Wiley Online Library.

Holness, M.B. (2018) Melt segregation from silicic crystal mushes: a critical appraisal of possible mechanisms and their microstructural record. Contributions to Mineralogy and Petrology, 173, 48, Springer.

Hooft, E.E.E., Heath, B.A., Toomey, D.R., Paulatto, M., Papazachos, C.B., Nomikou, P., Morgan, J.V., et al. (2019) Seismic imaging of Santorini: Subsurface constraints on caldera collapse and present-day magma recharge. Earth and Planetary Science Letters, 514, 48-61. doi:10.1016/j.epsl.2019.02.033

Huang, H.-H., Lin, F.-C., Schmandt, B., Farrell, J., Smith, R.B. \& Tsai, V.C. (2015) The Yellowstone magmatic system from the mantle plume to the upper crust. Science, 348, 773-776, American Association for the Advancement of Science.

Huber, C., Bachmann, O. \& Dufek, J. (2011) Thermo-mechanical reactivation of locked crystal mushes: Melting-induced internal fracturing and assimilation processes in magmas. Earth and Planetary Science Letters, 304, 443-454. doi:10.1016/j.epsl.2011.02.022

Hurwitz, S. \& Navon, O. (1994) Bubble nucleation in rhyolitic melts: Experiments at high pressure, temperature, and water content. Earth and Planetary Science Letters, 122, 267-280, Elsevier.

Jousset, P., Neuberg, J. \& Jolly, A. (2004) Modelling low-frequency volcanic earthquakes in a viscoelastic medium with topography. Geophysical Journal International, 159, 776-802. doi:10.1111/j.1365-246X.2004.02411.x

Jousset, P., Neuberg, J. \& Sturton, S. (2003) Modelling the time-dependent frequency content of lowfrequency volcanic earthquakes. Journal of Volcanology and Geothermal Research Putting Volcano Seismology in a Physical Context. In memory of Bruno Martinelli, 128, 201-223. doi:10.1016/S0377-0273(03)00255-5 
Karlstrom, L. \& Dunham, E.M. (2016) Excitation and resonance of acoustic-gravity waves in a column of stratified, bubbly magma. Journal of Fluid Mechanics, 797, 431-470, Cambridge University Press. doi:10.1017/jfm.2016.257

Karlstrom, L., Rudolph, M.L. \& Manga, M. (2012) Caldera size modulated by the yield stress within a crystal-rich magma reservoir. Nature Geoscience, 5, 402-405, Nature Publishing Group.

Kieffer, S.W. (1977) Sound speed in liquid-gas mixtures: Water-air and water-steam. Journal of Geophysical research, 82, 2895-2904, Wiley Online Library.

Kiser, E., Levander, A., Zelt, C., Schmandt, B. \& Hansen, S. (2018) Focusing of melt near the top of the Mount St. Helens (USA) magma reservoir and its relationship to major volcanic eruptions. Geology, 46, 775-778, GeoScienceWorld.

Kumagai, H. \& Chouet, B.A. (2000) Acoustic properties of a crack containing magmatic or hydrothermal fluids. Journal of Geophysical Research: Solid Earth, 105, 25493-25512, Wiley Online Library.

Kuster, G.T. \& Toksöz, M.N. (1974) Velocity and attenuation of seismic waves in two-phase media: Part I. Theoretical formulations. Geophysics, 39, 587-606, Society of Exploration Geophysicists.

Kytömaa, H.K. (1995) Theory of sound propagation in suspensions: a guide to particle size and concentration characterization. Powder Technology, 82, 115-121, Elsevier.

Lensky, N.G., Navon, O. \& Lyakhovsky, V. (2004) Bubble growth during decompression of magma: experimental and theoretical investigation. Journal of Volcanology and Geothermal Research, 129, 7-22, Elsevier.

Li, J. \& Mason, D.J. (2000) A computational investigation of transient heat transfer in pneumatic transport of granular particles. Powder Technology, 112, 273-282, Elsevier.

Mader, H.M., Llewellin, E.W. \& Mueller, S.P. (2013) The rheology of two-phase magmas: A review and analysis. Journal of Volcanology and Geothermal Research, 257, 135-158, Elsevier. 
Makse, H.A., Gland, N., Johnson, D.L. \& Schwartz, L. (2004) Granular packings: Nonlinear elasticity, sound propagation, and collective relaxation dynamics. Physical Review E, 70, 061302, APS.

Margulies, T.S. \& Schwarz, W.H. (1994) A multiphase continuum theory for sound wave propagation through dilute suspensions of particles. The Journal of the Acoustical Society of America, 96, 319-331, Acoustical Society of America. doi:10.1121/1.410482

Martel, C., Pichavant, M., Holtz, F., Scaillet, B., Bourdier, J.-L. \& Traineau, H. (1999) Effects of f O2 and $\mathrm{H} 2 \mathrm{O}$ on andesite phase relations between 2 and 4 kbar. Journal of Geophysical Research: Solid Earth, 104, 29453-29470, Wiley Online Library.

Marzougui, D., Chareyre, B. \& Chauchat, J. (2015) Microscopic origins of shear stress in dense fluidgrain mixtures. Granular Matter, 17, 297-309, Springer.

Mavko, G.M. (1980) Velocity and attenuation in partially molten rocks. Journal of Geophysical Research: Solid Earth, 85, 5173-5189, Wiley Online Library.

Morrissey, M.M. \& Chouet, B.A. (2001) Trends in long-period seismicity related to magmatic fluid compositions. Journal of Volcanology and Geothermal Research, 108, 265-281.

doi:10.1016/S0377-0273(00)00290-0

Neuberg, J. \& O’Gorman, C. (2002) A model of the seismic wavefield in gas-charged magma: application to Soufrière Hills Volcano, Montserrat. Geological Society, London, Memoirs, 21, 603-609, Geological Society of London. doi:10.1144/GSL.MEM.2002.021.01.29

Pallister, J.S., Hoblitt, R.P., Meeker, G.P., Knight, R.J. \& Siems, D.F. (1996) Magma mixing at Mount Pinatubo: petrographic and chemical evidence from the 1991 deposits. Fire and mud: eruptions and lahars of Mount Pinatubo, Philippines, 687-731, PHIVOLCS and University of Washington, Seattle.

Parmigiani, A., Faroughi, S., Huber, C., Bachmann, O. \& Su, Y. (2016) Bubble accumulation and its role in the evolution of magma reservoirs in the upper crust. Nature, 532, 492-495, Nature Publishing Group. doi:10.1038/nature17401 
Paulatto, M., Annen, C., Henstock, T.J., Kiddle, E., Minshull, T.A., Sparks, R.S.J. \& Voight, B. (2012) Magma chamber properties from integrated seismic tomography and thermal modeling at Montserrat. Geochemistry, Geophysics, Geosystems, 13, Wiley Online Library.

Petford, N. (2009) Which effective viscosity? Mineralogical Magazine, 73, 167-191, GeoScienceWorld.

Ranz, W.E. (1952) Evaporation from drops, Parts I \& II. Chem Eng Prog., 48, 141-146.

Rienstra, S.W. \& Hirschberg, A. (2004) An introduction to acoustics, Technische Universiteit Eindhoven.

Rothery, D.A., Sumner, J.M., Spieler, O. \& Dingwell, D.B. (2007) Impact vesiculation? a new trigger for volcanic bubble growth and degassing. eEarth Discussions, 2, 151-167.

Shea, T. (2017) Bubble nucleation in magmas: a dominantly heterogeneous process? Journal of Volcanology and Geothermal Research, 343, 155-170, Elsevier.

Syamlal, M., Rogers, W. \& OBrien, T.J. (1993) MFIX documentation theory guide, USDOE Morgantown Energy Technology Center, WV (United States).

Takahashi, R. \& Nakagawa, M. (2013) Formation of a compositionally reverse zoned magma chamber: Petrology of the ad 1640 and 1694 eruptions of Hokkaido-Komagatake volcano, Japan. Journal of Petrology, 54, 815-838, Oxford University Press.

Takei, Y. (2002) Effect of pore geometry on VP/VS: From equilibrium geometry to crack. Journal of Geophysical Research: Solid Earth, 107, ECV 6-1-ECV 6-12, Wiley Online Library.

Temkin, S. (1998) Sound propagation in dilute suspensions of rigid particles. The Journal of the Acoustical Society of America, 103, 838-849, Acoustical Society of America. doi:10.1121/1.421244

Temkin, S. (2000) Attenuation and dispersion of sound in dilute suspensions of spherical particles. The Journal of the Acoustical Society of America, 108, 126-146, Acoustical Society of America. doi:10.1121/1.429450 
Toramaru, A. (1995) Numerical study of nucleation and growth of bubbles in viscous magmas. Journal of Geophysical Research: Solid Earth, 100, 1913-1931. doi:10.1029/94JB02775

Valier-Brasier, T., Conoir, J.-M., Coulouvrat, F. \& Thomas, J.-L. (2015) Sound propagation in dilute suspensions of spheres: Analytical comparison between coupled phase model and multiple scattering theory. The Journal of the Acoustical Society of America, 138, 2598-2612, Acoustical Society of America.

Van den Wildenberg, S., Hecke, M. van \& Jia, X. (2013) Evolution of granular packings by nonlinear acoustic waves. EPL (Europhysics Letters), 101, 14004, IOP Publishing.

Waite, G.P. \& Moran, S.C. (2009) VP Structure of Mount St. Helens, Washington, USA, imaged with local earthquake tomography. Journal of Volcanology and Geothermal Research, 182, 113-122. doi:10.1016/j.jvolgeores.2009.02.009

Wen, C.Y. \& Yu, Y.H. (1966) A generalized method for predicting the minimum fluidization velocity. AIChE Journal, 12, 610-612, American Institute of chemical engineers New York.

Wiebe, R.A. (2016) Mafic replenishments into floored silicic magma chambers. American Mineralogist, 101, 297-310. doi:10.2138/am-2016-5429

Zhang, Y. \& Behrens, H. (2000) H2O diffusion in rhyolitic melts and glasses. Chemical Geology, 169, 243-262. doi:10.1016/S0009-2541(99)00231-4 


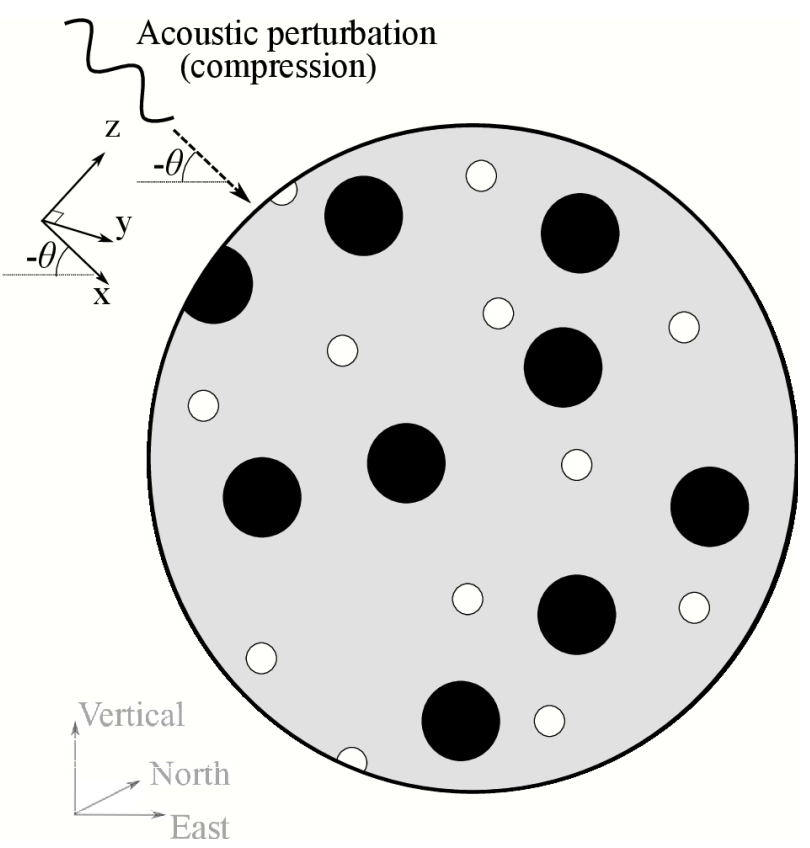

663 Figure 1: Schematic representation of a suspension of solid particles and gas bubbles in a viscous 664 liquid. The scheme represents a cross-section of an elementary volume perpendicular to the north 665 direction. The liquid phase is represented in gray. The black and white disks correspond to the solid 666 particles and gas bubbles, respectively. The three gray axes (east, north, and vertical) indicate the 667 orientation with respect to the gravitational acceleration vector. The black orientation axes $(x, y$, and $z)$ 668 indicate the coordinate system used to express the conservation equations, in which the direction $x$ is 669 aligned in the direction of the propagation of the wave. The sinusoid represents the plane acoustic 670 perturbation propagating along the direction $x$ with an angle $\theta$ (positive clockwise) from the east 671 direction. 


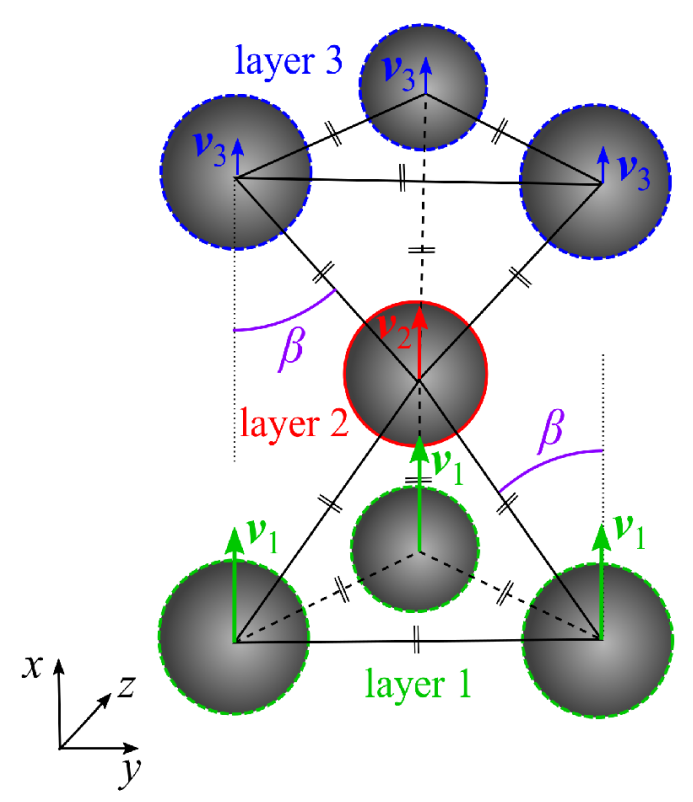

674 Figure 2: Conceptual configuration of the crystals used to derive the rate of momentum exchange

675 between the solids. The scheme represents one target particles located in the layer 2 and its six closest

676 neighbors located in the layer 1 and 3. The color of the boundary of each particle depends on the layer

677 in which it is located (green for layer 1, red for layer 2, and blue for layer 3). Each arrow indicates the 678 velocity vector of the corresponding particles. The grazing angle $\beta$ is represented in purple. 

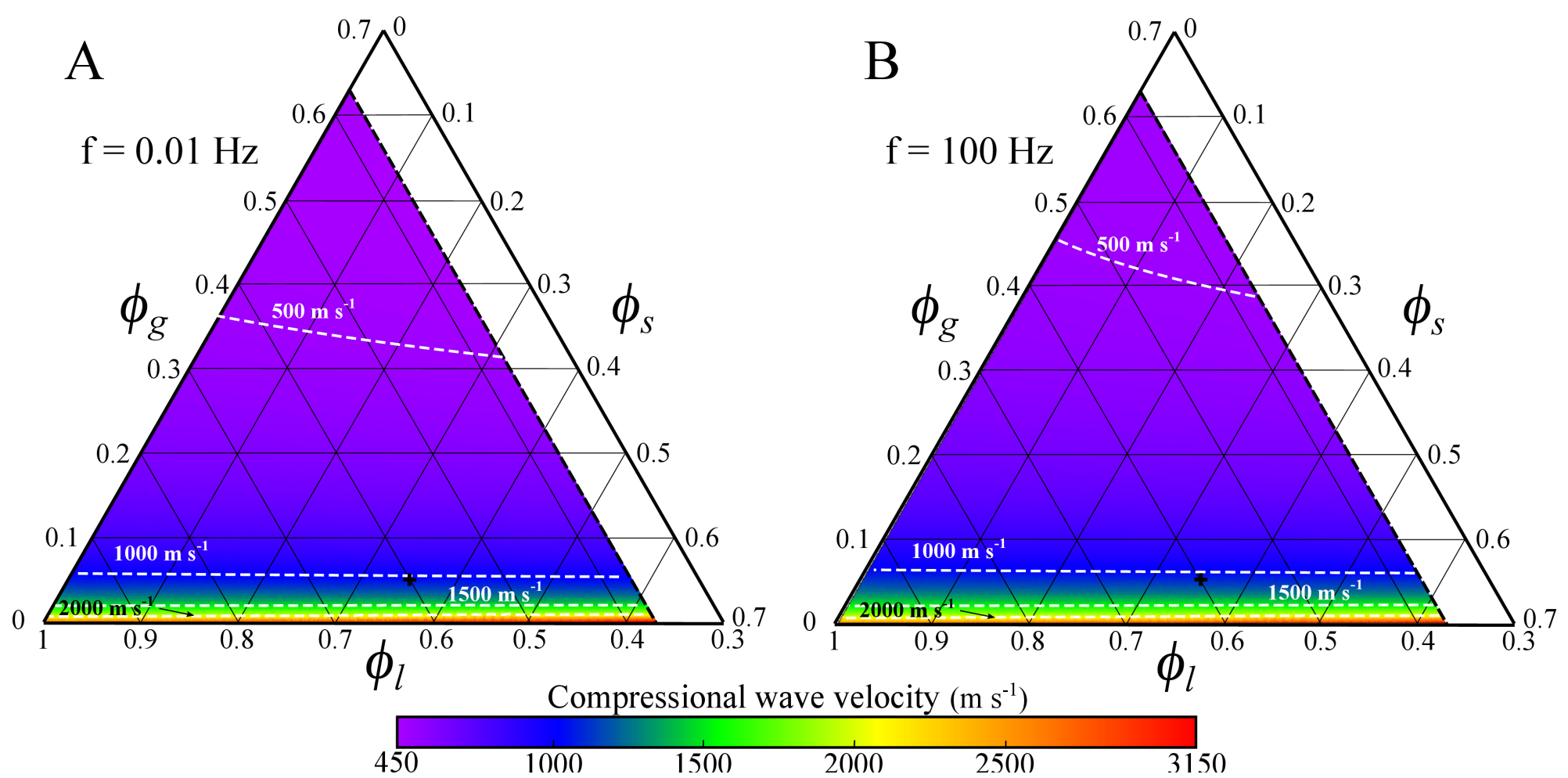

680 Figure 3: Speed of sound as a function of the volume fraction in liquid, solids, and gas when $f=0.01 \mathrm{~Hz}$

681 (A) and $f=100 \mathrm{~Hz}$ (B). The background color depends on the velocity of compressional waves. The

682 white dashed curves indicate isocontours of the sound speed. The black dash line indicates the

683 theoretical limit of the validity of the model at $\phi_{l}=0.36$. The material properties of the constituents and

684 the incidence angle are indicated in Table 2. The black cross indicates the volume fractions used to 685 compute the dispersion curve in Fig.3.

686 


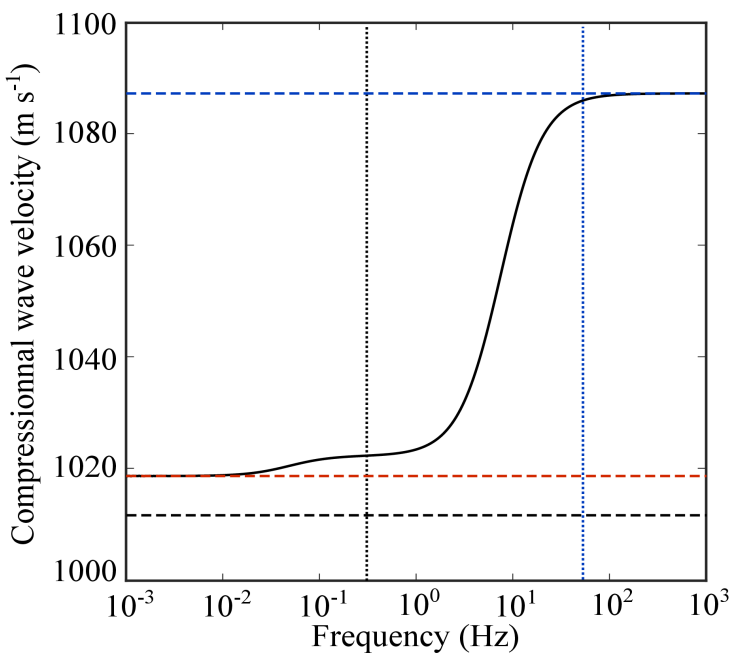

688 Figure 4: Dispersion curve of a magmatic suspension. The volume fraction of the constituents are $\phi_{l}=$ $6890.6, \phi_{s}=0.35$, and $\phi_{g}=0.05$. The solid black curve indicates the results obtained with Eq. (35). The 690 black, red, and blue dashed lines indicate the isothermal speed of sound (Eq. 42), the isentropic speed 691 of sound at thermal equilibrium (Eq. 47), and isentropic speed of sound out of thermal equilibrium (Eq. 692 45), respectively. The black and blue vertical doted lines indicate the critical frequencies above which 693 the solid and gas bubbles are not in thermal equilibrium with the surrounding liquid, respectively (Eqs. 69440 and 41). The material properties of the constituents and the incidence angle are indicated in Table 2.

695

696 


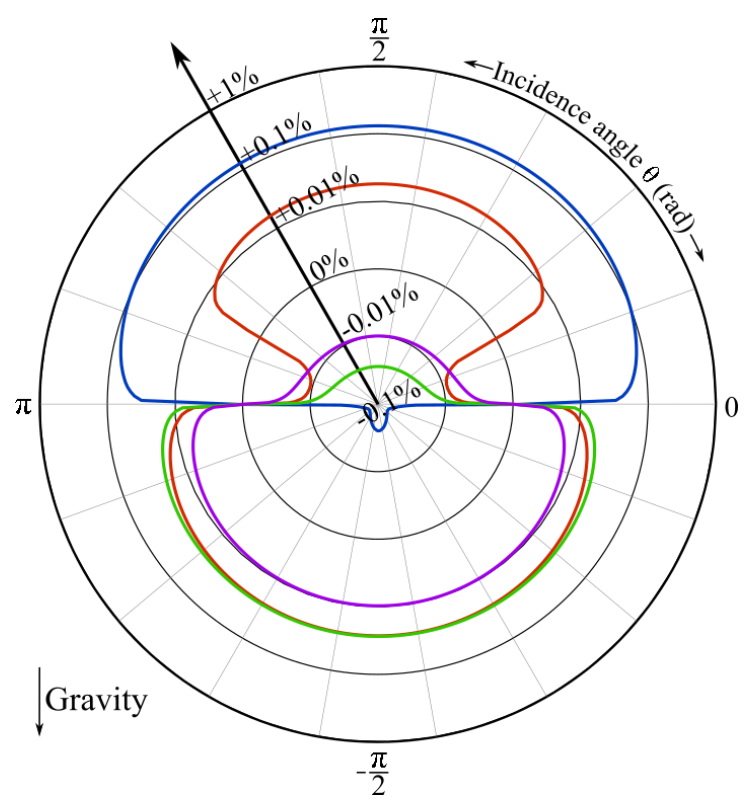

697 Figure 5: Evolution of the compression wave velocity as a function of the incidence angle and 698 frequency of the perturbation. The radial axis indicates the difference in \% between the velocity of the 699 compressional wave at $\theta$ and $\theta=0$. The blue, red, green, and purple curves correspond to frequencies of $7000.01 \mathrm{~Hz}, 0.1 \mathrm{~Hz}, 1 \mathrm{~Hz}$, and $10 \mathrm{~Hz}$, respectively. The volume fraction of the constituents are $\phi_{l}=0.65, \phi_{s}=$ 7010.3 and $\phi_{g}=0.05$. The material properties of the constituents are indicated in Table 2 . 

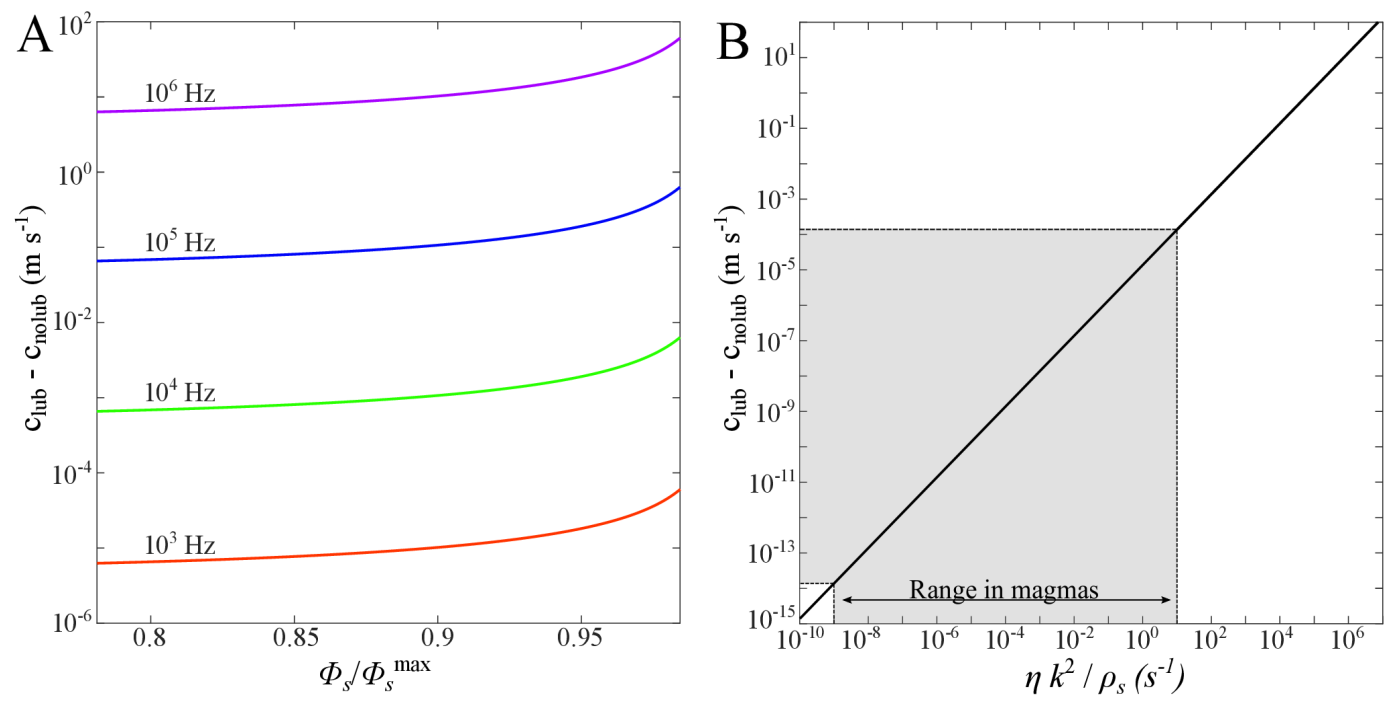

704 Figure 6: Influence of the lubrication forces on the speed of sound in a suspension of solid particles in 705 a viscous fluid. [A] Difference between the speed of sound computed with Eq. (35) considering and 706 neglecting lubrication forces. The physical properties of the liquid and solids are the ones indicated in 707 Table 2. [B] Evolution of the difference between the speed of sound computed with Eq. (35) 708 considering $\left(c_{l u b}\right)$ and neglecting $\left(c_{n o l u b}\right)$ lubrication forces as a function of $\eta k^{2} / \rho_{s}$. The shaded area 709 indicates the area covered by magmas. 

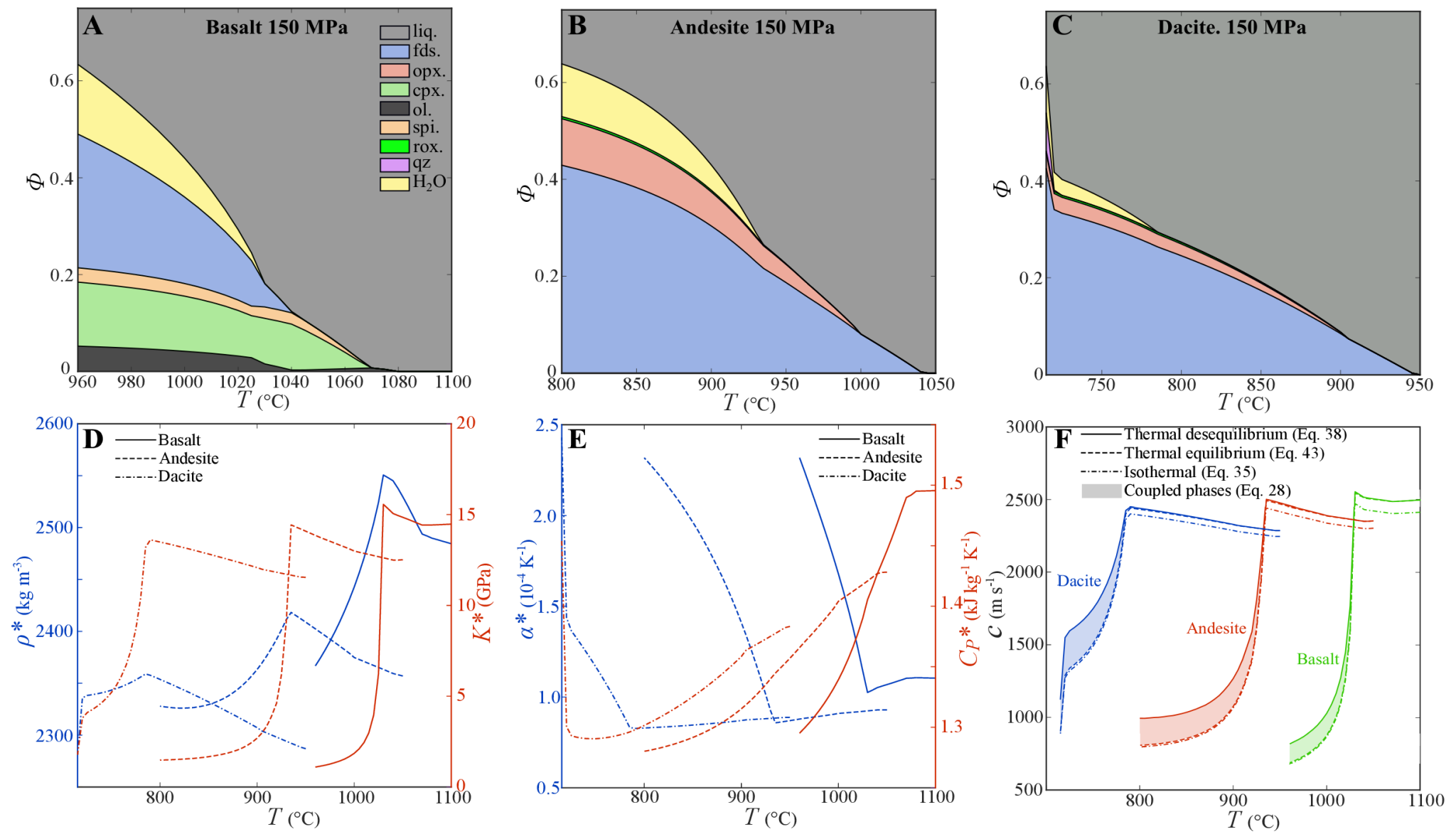

710 Figure 7: Evolution of the phase assemblage, thermodynamic properties, and speed of sound of the

711 magmas during the cooling simulations. $[\mathbf{A}],[\mathbf{B}]$, and $[\mathbf{C}]$ are the phases assemblage computed during

712 the simulation of the cooling of the basalt (A), andesite (B), and dacite (C). [D] evolution of the bulk

713 densities and bulk moduli of the magmas. [E] Evolution of the bulk coefficient of thermal expansion

714 and bulk heat capacity at constant pressure as a function of temperature. [F] Evolution of the speed of

715 sound in the magmas. The solid, dashed and dashed-doted curves indicate the thermal disequilibrium,

716 thermal equilibrium, and isothermal bounds, respectively. The shaded area corresponds to the range of

717 velocity that may be computed with Eq. (35) at different frequencies. 


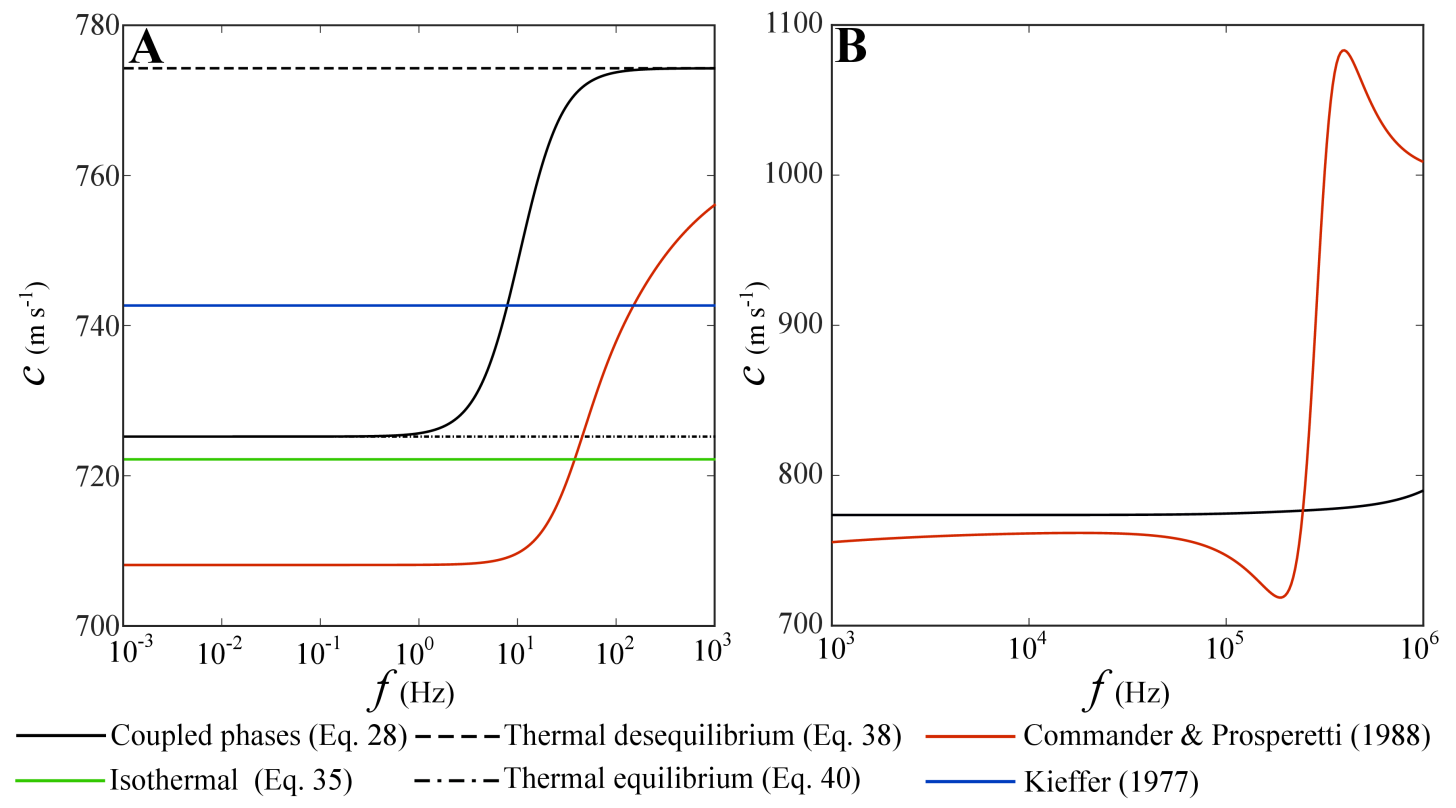

719 Figure 8: [A] Comparison of sound speeds predicted by various model in a suspension of gas bubbles 720 in water for $10^{-3} \leq f \leq 10^{3} \mathrm{~Hz}$. [B] Comparison of the speed of sound computed with Eq. (35) and with Eq. 721 (41) in Commander \& Prosperetti (1988) for $10^{3} \leq f \leq 10^{6}$. The properties of the fluid are the same as in 722 (A). The density of the water and gas were calculated following Eq. (8) and (9) in Kieffer (1977). The 723 bulk modulus and coefficient of thermal expansion, $K_{g}=P, \alpha_{g}=1 / T$. The heat capacity of the gas is 724 calculated as $C_{P g}=(\gamma /(\gamma-1)) R / M_{g}$, where $\gamma$ is the heat capacity ratio $(\gamma=1.4), R$ is the ideal gas constant, 725 and $M_{g}$ is the molar mass of the gas. 
726 Table 1: Initial chemical composition, pressure, and temperature of the magmas.

\begin{tabular}{|c|c|c|c|}
\hline Composition wt\% & Basalt & Andesite & Dacite \\
\hline $\mathrm{SiO}_{2}$ & 48.108 & 59.736 & 66.013 \\
\hline $\mathrm{TiO}_{2}$ & 0.970 & 0.469 & 0.440 \\
\hline $\mathrm{Al}_{2} \mathrm{O}_{3}$ & 16.883 & 17.341 & 15.263 \\
\hline $\mathrm{Fe}_{2} \mathrm{O}_{3}$ & 1.755 & 1.277 & 0.663 \\
\hline $\mathrm{FeO}$ & 8.279 & 4.765 & 2.031 \\
\hline $\mathrm{MnO}$ & 0.174 & 0.176 & 0.069 \\
\hline $\mathrm{MgO}$ & 5.925 & 2.239 & 0.908 \\
\hline $\mathrm{CaO}$ & 10.396 & 6.100 & 2.910 \\
\hline $\mathrm{Na}_{2} \mathrm{O}$ & 2.657 & 3.451 & 3.691 \\
\hline $\mathrm{K}_{2} \mathrm{O}$ & 1.193 & 1.026 & 4.004 \\
\hline $\mathrm{P}_{2} \mathrm{O}_{5}$ & 0.214 & 0.000 & 0.186 \\
\hline $\mathrm{H}_{2} \mathrm{O}$ & 3.447 & 3.4213 & 3.435 \\
\hline T start $\left({ }^{\circ} \mathrm{C}\right)$ & 1100 & 1050 & 950 \\
\hline T stop $\left({ }^{\circ} \mathrm{C}\right)$ & 960 & 700 & 715 \\
\hline $\mathrm{P}(\mathrm{Mpa})$ & 150 & 150 & 150 \\
\hline $\mathrm{fO}_{2}$ buffer & QFM & $\mathrm{Ni}-\mathrm{NiO}$ & $\mathrm{Ni}-\mathrm{NiO}$ \\
\hline Source & Dufek \& Bachmann (2010) & Martel et al. (1999) & Dufek \& Bachmann (2010) \\
\hline
\end{tabular}


728 Table 2: Reference physical properties used to explore the influence of the composition of the 729 suspension and characteristics of the perturbation on the speed of sound. They correspond to an 730 approximate total pressure of $150 \mathrm{MPa}$.

\begin{tabular}{|c|c|}
\hline Variable & Reference value \\
\hline $\bar{T}$ & $1000^{\circ} \mathrm{C}$ \\
\hline$\rho_{l}^{0}$ & $2500 \mathrm{~kg} \mathrm{~m}^{-3}$ \\
\hline$\rho_{s}{ }^{0}$ & $3000 \mathrm{~kg} \mathrm{~m}^{-3}$ \\
\hline$\rho_{g}{ }^{0}$ & $350 \mathrm{~kg} \mathrm{~m}^{-3}$ \\
\hline$K_{l}$ & $15 \mathrm{GPa}$ \\
\hline$K_{s}$ & $50 \mathrm{GPa}$ \\
\hline$K_{g}$ & $150 \mathrm{MPa}$ \\
\hline$\eta$ & $1000 \mathrm{~Pa} \mathrm{~s}$ \\
\hline$C_{P l}$ & $1300 \mathrm{~J} \mathrm{~kg}^{-1} \mathrm{~K}^{-1}$ \\
\hline$C_{P s}$ & $1200 \mathrm{~J} \mathrm{~kg}^{-1} \mathrm{~K}^{-1}$ \\
\hline$C_{P g}$ & $3750 \mathrm{~J} \mathrm{~kg}^{-1} \mathrm{~K}^{-1}$ \\
\hline$\alpha_{l}$ & $10^{-4} \mathrm{~K}^{-1}$ \\
\hline$\alpha_{s}$ & $10^{-6} \mathrm{~K}^{-1}$ \\
\hline$\alpha_{g}$ & $10^{-3} \mathrm{~K}^{-1}$ \\
\hline$k_{l}$ & $1 \mathrm{~W} \mathrm{~m}^{-1} \mathrm{~K}^{-1}$ \\
\hline$d_{s}$ & $5 \mathrm{~mm}$ \\
\hline$d_{g}$ & $0.5 \mathrm{~mm}$ \\
\hline$g$ & $-9.81 \mathrm{~m} \mathrm{~s}^{-2}$ \\
\hline$\theta$ & $0^{\circ}$ \\
\hline
\end{tabular}

731

732

733

734

735 Table 3: List of the thermodynamical properties, or expressions employed to estimate them, used to

736 compare the different models in Fig. 6. The surface tension at the interfaces between the bubbles and

737 liquid is neglected. The thermodynamic properties and relationships are taken from Kieffer (1977). 


\begin{tabular}{ll}
\hline Parameters & Expression or value \\
\hline$\rho_{l}{ }^{0}$ & $1000 \mathrm{~kg} \mathrm{~m}^{-3}$ \\
$\rho_{g}{ }^{0}$ & $\rho_{g}^{0}=\left(\frac{P}{G_{a i r}}\right)^{\frac{1}{\gamma}}$ \\
$\rho_{g}{ }^{r e f}$ & $690 \mathrm{~kg} \mathrm{~m}^{-3}$ \\
$G_{a i r}$ & $G_{a i r}=\frac{T R}{M_{g} \rho_{g}{ }^{r e f \gamma^{-1}}}$ \\
$T$ & $20{ }^{\circ} \mathrm{C}$ \\
$P$ & $500 \mathrm{bars}$ \\
$\gamma$ & 1.4 \\
$d_{g}$ & $0.5 \mathrm{~mm}$ \\
$\eta$ & $10 \mathrm{~Pa} \mathrm{~s}$ \\
$M g$ & $29.9810^{-3} \mathrm{~kg} \mathrm{~mol}^{-1}$ \\
$C_{P l}$ & $1300 \mathrm{~J} \mathrm{~kg}^{-1} \mathrm{~K}^{-1}$ \\
$C_{P g}$ & $C_{P g}=\frac{R}{M_{g}}\left(1-\frac{1}{\gamma}\right)$ \\
$K_{f}$ & $1 \mathrm{GPa}$ \\
$K_{g}$ & $K_{g}=P$ \\
$\alpha_{l}$ & $110^{-4} \mathrm{~K}^{-1}$ \\
$\alpha_{g}$ & $\alpha_{g}=1 / T$ \\
\hline
\end{tabular}

738

739 